Revista Brasileira de Informática na Educação - RBIE Brazilian Journal of Computers in Education (ISSN online: 2317-6121; print: 1414-5685) http://br-ie.org/pub/index.php/rbie

Submission: 10/Jul/2021;

Camera ready: 01/Dec/2021; $1^{\text {st }}$ round notif.: $10 / \mathrm{Aug} / 2021$;

Edition review: 21/Dec/2021;
New version: 30/Aug/2021; Available online: 22/Dec/2021; $2^{\text {nd }}$ round notif: $14 / \mathrm{Sep} / 2021$;

Published: 22/Dec/2021;

\title{
Percepção do Ensino-Aprendizagem da Monitoria de Algoritmos e Programação em Cursos de Engenharia na Perspectiva de Estudantes, Monitores e Professores
}

\section{Title: Perception of Teaching-Learning of Algorithm Monitoring and Programming in Engineering Courses from the Perspective of Students, Monitors and Professors}

\author{
José Solenir Lima Figuerêdo \\ Departamento de Ciências Exatas \\ Universidade Estadual de Feira de Santana \\ ORCID: 0000-0003-1892-3455 \\ jslfigueredo@ecomp.uefs.br \\ Samuel Vitório Lima \\ Departamento de Ciências Exatas \\ Universidade Estadual de Feira de Santana \\ samvlima10@gmail.com \\ Claudia Pinto Pereira \\ Departamento de Ciências Exatas \\ Prog. de Pós-Graduação em Ciência da Computação \\ Universidade Estadual de Feira de Santana \\ ORCID: 0000-0002-2552-2089 \\ claudiap@uefs.br
}

\author{
Jussara Gomes Machado \\ Prog. de Pós-Graduação em Ciência da Computação \\ Universidade Estadual de Feira de Santana \\ jussarauefs@gmail.com
}

Cláudio Sérgio da Silva Cerqueira

Departamento de Ciências Exatas

Universidade Estadual de Feira de Santana

csscerqueira@uefs.br

\section{Resumo}

A monitoria é caracterizada como uma modalidade de ensino e aprendizagem que auxilia na formação integrada dos estudantes. É considerada como uma oportunidade dos monitores desenvolverem habilidades relacionadas à docência, além de aprofundar conhecimentos na área específica. Contudo, a sua ação efetiva depende de muitos fatores que vão desde o interesse particular dos estudantes "monitorados" até à colaboração do professor da disciplina com o monitor. Assim, refletir e compreender como os estudantes "monitorados", estudantes monitores e professores enxergam a monitoria constitui-se uma atividade fundamental, especialmente para impulsionar melhorias. Deste modo, este estudo relata a experiência vivenciada por esses três diferentes atores, participantes de um projeto de monitoria que auxilia disciplinas que envolvem tópicos relacionados à lógica e ao raciocínio matemático, notadamente à programação de computadores. Os resultados revelam que, embora os estudantes "monitorados" tenham consciência da importância da monitoria, muitos não sentem a necessidade de procurar o monitor, muitas vezes recorrendo à internet e aos colegas para sanarem suas dúvidas. Além disso, os estudantes consideraram as disciplinas apoiadas pela monitoria como essenciais para alcançar seus objetivos profissionais, e acham a profissão de Computação divertida. Considerando os monitores, os nossos resultados revelaram que "Contribuir significativamente com o processo de aprendizagem de outros estudantes" e o "Interesse em ingressar na vida acadêmica/docente" são os principais motivos que levam os estudantes a entrarem no projeto de monitoria. Também indicaram que a monitoria permitiu melhorar suas estratégias de ensino, o conhecimento sobre linguagens de programação e a oralidade. Com relação aos professores, os nossos resultados mostram que os professores enxergam o projeto de monitoria como um recurso importante no processo de aprendizado do estudante. Contudo, verificou-se que, embora os professores estejam abertos ao projeto de monitoria, ainda falta uma maior interatividade entre esses e o estudante monitor.

Palavras-chave: Monitoria; ensino-aprendizagem; aprendizagem em pares; aprendizagem colaborativa; monitoria em engenharia; experiência com docência.

Cite as: Figuerêdo, J. S. L., Machado, J. G., Lima, S. V., Cerqueira, C. S. S., \& Pereira, C. P. (2021). Percepção do Ensino-Aprendizagem da Monitoria de Algoritmos e Programação em Cursos de Engenharia na Perspectiva de Estudantes, Monitores e Professores. Revista Brasileira de Informática na Educação, 29, 1433-1462. DOI: 10.5753/rbie.2021.2126. 


\begin{abstract}
Monitoring is characterized as a teaching and learning modality that helps in the integrated formation of students. It is considered an opportunity for monitors to develop skills related to teaching, beyond the deepening knowledge in the specific area. However, its effective action depends on many factors ranging from the particular interest of the "monitored" students to the collaboration of the discipline professor with the monitor. Therefore, reflecting and understanding how "monitored" students, student monitors, and professors see monitoring is a fundamental activity, especially to drive improvements. Thus, this study describes the experience lived by these three different actors, participants in a monitoring project that helps disciplines involving topics related to logic and mathematical reasoning, notably computer programming. The results reveal that, although the "monitored" students are aware of the importance of monitoring, many do not feel the need to seek the monitor, often resorting to the internet and colleagues to resolve their doubts. In addition, students considered the disciplines supported by tutoring as essential to achieving their professional goals, and think the computing profession fun. Considering the monitors, our results revealed that "Contributing significantly to the learning process of other students" and "Interest in entering academic/faculty life" are the main reasons that lead students to enter the project of monitoring. They also indicated that monitoring allowed them to improve their teaching strategies, knowledge of programming languages, and orality. Concerning professors, our results show that they see the monitoring project as an important resource in the student's learning process. However, it was found that, although professors are open to the monitoring project, there is still a lack of greater interactivity between them and the student monitor.
\end{abstract}

Keywords: Monitoring; teaching-learning; peer learning; collaborative learning; engineering monitoring; teaching experience.

\title{
1 Introdução
}

Nas últimas décadas, o ensino superior no Brasil passou por um intenso processo de expansão. Entre 2007 e 2017, houve um aumento de 56,4\% na matrícula do ensino superior (INEP, 2017). Contudo, embora se observe esse aspecto positivo no ensino superior brasileiro, alguns problemas ainda persistem, como de estrutura física, formação de professores, redução orçamentária, além dos altos índices de evasão e reprovação, sendo os cursos de engenharia os mais afetados neste último caso (Reis et al., 2012).

Ao ingressarem no ensino superior, uma nova realidade é apresentada aos estudantes, especialmente com relação às disciplinas e aos conteúdos, os quais muitas vezes se distanciam daquilo que estavam habituados. Isso pode ser presenciado em diferentes cursos, mas de modo especial nas engenharias, com os estudantes novatos, os quais precisam se adaptar à universidade, com suas características e particularidades, bem como aos novos componentes curriculares e suas diversidades (INEP, 2010). A adaptação envolve diferentes dimensões, que vão desde aspectos pessoais a cognitivos. Esse processo de transformação está longe de ser trivial, por diferentes motivos, tais como as experiências pessoais anteriores, as fragilidades na escolaridade anterior, as dificuldades de relacionamento, de interpretação de problemas, de raciocínio lógico matemático, de abstração e outros (Piva Júnior \& Freitas, 2010; Godoy \& Almeida, 2017).

Disciplinas que naturalmente estão envolvidas com o pensamento computacional, como programação de computadores, são exemplos de disciplinas que exigem a capacidade de interpretação e a abstração por parte dos discentes (Zanetti \& Oliveira, 2015; Ribeiro et al., 2017). Considerada como uma competência/habilidade complexa de se aprender, a programação de computadores exige diferentes variedades de conhecimentos, estratégias e modelos nos diferentes níveis de domínio do problema, do design de solução e do programa propriamente dito (Robins et al., 2003). Assim, disciplinas que envolvem programação ou, até mesmo, o uso do pensamento computacio- 
nal acabam por apresentar altos índices de abandono e reprovação (Watson \& Li, 2014).

Para atenuar esses problemas, uma série de medidas podem ser empregadas, sejam institucionais, curriculares, docentes e discentes, tais como, monitoria, estudos individuais sistematizados ou em grupo, prática de exercícios, projetos disciplinares ou interdisciplinares, estágio supervisionado e/ou não supervisionado e organização de tempo (Bazzo \& Pereira, 2010). A aplicação contínua dessas estratégias pode contribuir para minimizar as dificuldades enfrentadas pelos estudantes. Em nosso contexto, tem-se interesse nas atividades relacionadas à monitoria. A monitoria pode ser compreendida como uma modalidade de ensino e aprendizagem que contribui para a formação integrada dos estudantes nas atividades de ensino, pesquisa e extensão dos cursos de graduação (Lins et al., 2009). A monitoria tem um importante papel nos cursos de graduação, especialmente pela estreita relação existente entre o aluno e o monitor, o que contribui mutuamente para o desenvolvimento de ambos, devido à troca de informações que pode haver entre si.

A estreita relação entre monitor e os demais estudantes proporcionada pela monitoria faz desta estratégia uma importante ferramenta para os cursos de graduação. A troca mútua de informações que pode haver contribui para o desenvolvimento de ambos. O estudante precisa do conhecimento adquirido pelo monitor para solucionar uma dúvida, e este, por sua vez, precisa desse conhecimento para ajudar a solucionar a dúvida apresentada pelo aluno (Silveira \& Sales, 2016). Esse aspecto colaborativo da monitoria é bem peculiar comparado a outras atividades pedagógicas, pois os dois envolvidos neste processo serão "recompensados". Conforme apontado em Silveira \& Sales (2016), o estudante tem a oportunidade de aprender com o auxílio do monitor, enquanto o monitor poderá adquirir mais experiência e terá a oportunidade de fixar ainda mais o conteúdo. Além disso, no papel de docente, o estudante monitor pode obter uma visão mais ampla sobre determinado assunto, podendo levá-lo a um aprofundamento daquele conteúdo ou, até mesmo, uma ressignificação.

Contudo, embora a monitoria seja uma realidade em grande parte das universidades brasileiras, e haja um consenso da sua importância como um instrumento no processo de ensino e aprendizagem, esta estratégia acadêmica ainda não é popular entre o meio discente (Cunha Júnior, 2017). Por conseguinte, muitas oportunidades de melhorias do programa em articulação com o ensino não são bem aproveitadas ou são pouco utilizadas (Amato \& Reis, 2016). Dessa forma, estudos que investiguem aspectos relacionados a essa atividade são pertinentes, uma vez que podem contribuir para melhor compreensão de como a monitoria está sendo desenvolvida, levando ao aprimoramento contínuo dessa atividade tão importante à excelência acadêmica.

Diante do cenário apresentado, este artigo relata a experiência vivenciada pelos estudantes "monitorados", estudantes monitores e professores vinculados à monitoria de algoritmos e programação da Universidade Estadual de Feira de Santana (UEFS), apontando as principais percepções adquiridas ao longo do desenvolvimento do projeto de monitoria. Com relação aos estudantes monitores, também são apresentadas as principais lições aprendidas, assim como um conjunto de possíveis estratégias pedagógicas que poderiam ser aplicadas, a fim de minimizar os problemas presentes nas disciplinas contempladas pela monitoria, comumente relacionados à programação de computadores. Ao concentrar este relato nos três principais atores envolvidos com a monitoria, é esperado obter uma visão ampla do desenvolvimento do projeto, visando traçar estratégias que possibilitem a sua melhoria contínua. Espera-se ainda que estudos semelhantes possam ser realizados em projetos similares. 
As diferentes atividades, executadas ao longo dos anos pela monitoria de algoritmos e programação da UEFS, foram sempre planejadas de modo a implementar metodologias de aprendizagem que facilitassem a retenção de conhecimentos por parte dos estudantes monitorados. Como relatado por Diesel et al. (2018), a aplicação de metodologias de ensino que foquem na interação entre os sujeitos, bem como no protagonismo e postura crítica e autônoma dos estudantes, contribuem para um ambiente favorável à aprendizagem.

\section{Fundamentação Teórica}

Nesta seção, aborda-se brevemente uma visão geral da monitoria acadêmica no Brasil, assim como no âmbito da instituição, na qual este estudo foi realizado. Além disso, apresentam-se as principais metodologias de aprendizagem relacionadas às práticas pedagógicas envolvidas na monitoria que foram pesquisadas.

\subsection{Monitoria acadêmica no Brasil}

A monitoria acadêmica no Brasil foi inicialmente proposta através da Lei n. ${ }^{0}$ 5.540/68, que fixa normas de organização e funcionamento do ensino superior e sua articulação com a escola média (Brasil, 1968). Em seu art. 41, a lei estabelecia que: "As universidades deverão criar as funções de monitor para alunos do curso de graduação que se submeterem a provas específicas, nas quais demonstrem capacidade de desempenho em atividades técnico-didáticas de determinada disciplina. Parágrafo único. As funções de monitor deverão ser remuneradas e consideradas título para posterior ingresso em carreira de magistério superior".

Posteriormente, em 1981, a monitoria acadêmica voltou a ser citada no Decreto de $\mathrm{n}^{\circ} 85.862$, depois revogado, que atribuía competência às Instituições de Ensino Superior para fixar as condições necessárias ao exercício das funções de monitoria e dá outras providências (Brasil, 1981). Mais recentemente, a Lei ${ }^{\circ}$ 9.394, que estabelece as diretrizes e normas da educação nacional, define em seu art. 84 que: "Os discentes da educação superior poderão ser aproveitados em tarefas de ensino e pesquisa pelas respectivas instituições, exercendo funções de monitoria, de acordo com seu rendimento e seu plano de estudos" (Brasil, 1996). Desde a sua concepção, a monitoria acadêmica vêm contribuindo para que as universidades obedeçam ao princípio da indissociabilidade entre o ensino, a pesquisa e a extensão, expresso no art. 207 da Constituição de 1988 (Brasil, 1988), atuando sobre a perspectiva do ensino.

\subsubsection{Monitoria acadêmica na UEFS}

O Programa de Bolsa Monitoria da UEFS é regulamentada através da Resolução CONSEPE 208/2010 e responsabilidade da Pró-Reitoria de Ensino de Graduação (UEFS, 2010). Os sujeitos envolvidos neste programa são: os monitores bolsistas, os monitores voluntários, os professores orientadores e os discentes aprendentes. Os monitores, bolsistas e voluntários, são selecionados através de editais públicos. As seleções geralmente ocorrem em três etapas: a prova escrita, através da qual se avalia, entre outros aspectos, a capacidade de síntese e ordenação lógica do pensamento; a entrevista, momento no qual se identifica os interesses do candidato e demais aspectos 
relevantes à atividade de monitoria; e a prova de títulos, através da qual se avalia o desempenho acadêmico, bem como a participação do candidato em atividades extra-curriculares, a partir de um barema classificatório definido em edital. Tendo sido aprovado no processo seletivo, o discente monitor assume a responsabilidade de participar ativamente das atividades planejadas pelos professores orientadores, comumente: auxiliar o professor na realização de trabalhos práticos e experimentais, na preparação de material didático e em atividades de classe, laboratórios, workshops e trabalhos de campo (UEFS, 2021).

Os professores orientadores são os responsáveis por acompanhar, orientar e avaliar as atividades desenvolvidas pelos monitores. Eles também são responsáveis por fazer a solicitação anual do projeto, especificando, entre outras coisas, sua estrutura, justificativa, objetivos, o plano e as atividades a serem desenvolvidas (UEFS, 2021).

De acordo com o art. 3 da Resolução CONSEPE 208/2010, são objetivos do Programa de Bolsa Monitoria da UEFS: I. Proporcionar ao estudante de graduação, regularmente matriculado, a oportunidade de engajar-se em pleno trabalho de atividades de ensino que possibilitem o aperfeiçoamento do conhecimento e o desenvolvimento de atitudes e habilidades favoráveis à sua formação acadêmica e profissional; II. Criar condições de aperfeiçoamento teórico e desenvolvimento de habilidades relacionadas à atividade docente. III. Estabelecer práticas e experiências pedagógicas que permitam a integração dos estudantes monitores com o corpo docente, discente e técnico administrativo (UEFS, 2021).

Sobre a monitoria de algoritmos e programação, uma importante estratégia utilizada é a aplicação de metodologias de aprendizagem, como: a aprendizagem colaborativa, na qual os alunos experimentam a troca de conhecimentos; a aprendizagem significativa, em que os conteúdos são apresentados de forma estruturada e sempre fazendo relação com outros conteúdos; e a aprendizagem por pares, com a promoção de discussões sobre o assunto estudado.

\subsection{Metodologias de Aprendizagem}

Semelhante ao relatado por Cunha Júnior (2017), referente às escolas de ensino médio no Brasil, nas universidades se percebe um desnível de conhecimentos entre os alunos. Entre as justificativas, destacam-se as diferentes condições sociais dos alunos, condições tais que refletem principalmente na qualidade da sua formação acadêmica anterior (Gadotti, 2010; Dourado \& Oliveira, 2009; Gatti, 2016). Diante dessa realidade, torna-se necessária a implementação de projetos de intervenção que visem minimizar e colaborar com a solução do problema.

O Programa de monitoria surge, nesse aspecto, como uma estratégia de intervenção que promove uma aprendizagem colaborativa e significativa, levando os alunos envolvidos a entenderem os problemas sob uma perspectiva diferente e assim propor formas diferentes de solucioná-los (Frison, 2016; Galvani et al., 2017). O cenário em que se aplica essa forma de intervenção (alunos dispostos a melhorar, ambiente cooperativo e interativo, desconstrução da ideia de que o professor é o único detentor do conhecimento, etc.) possibilita a aplicação de metodologias de ensino que tornam o aluno o sujeito do seu processo de aprendizagem. 


\subsubsection{Aprendizagem Colaborativa}

A monitoria evolui de um processo cooperativo, em que individualmente os envolvidos desempenhavam suas atividades com foco em um produto final, para um processo colaborativo, no qual os envolvidos desenvolvem um processo síncrono de aprendizagem, focado na troca de experiências (Cunha Júnior, 2017). Para Lourenço \& Machado (2017), a aprendizagem colaborativa apresenta vantagens sociais porque ajuda a desenvolver um sistema de apoio social para alunos e a entender a diversidade entre as pessoas em interação. A colaboração, foco dessa metodologia, aumenta a autoestima, reduz a ansiedade e, no contexto de sala de aula, desenvolve nos alunos atitudes positivas em relação ao apresentador dos conteúdos.

Promover uma aprendizagem colaborativa envolve tornar o aprendente o agente do processo de aprendizagem, possibilitando que este reflita criticamente sobre as atividades em todas as suas fases. Isso significa dar autonomia e responsabilidade para a construção e a reconstrução das atividades, fazendo com que os aprendentes reconheçam seu poder de escolher o que ocorrerá em seguida (Cunha Júnior, 2017; Vasconcelos et al., 2003). Ainda segundo Cunha Júnior (2017), o processo de aprendizagem colaborativa se torna ainda mais eficaz quando o sujeito, ao se tornar agente, pode também contar com o apoio do seu colega.

\subsubsection{Aprendizagem Significativa}

A teoria da aprendizagem significativa, proposta por David Ausubel, enfatiza a aprendizagem por meio de significados (conceitos) como a mais relevante para os seres humanos (Ausubel, 1968). Essa forma de aprendizagem requer três importantes requisitos, sendo eles: a oferta de um conhecimento novo e estruturado de maneira lógica; a prévia existência de conhecimentos na estrutura cognitiva do aprendiz que possibilite uma conexão com o novo conhecimento; e a atitude de aprender e conectar seu prévio conhecimento com o que pretende absorver (Tavares, 2004).

A aprendizagem significativa, quando comparada com a aprendizagem mecânica, ou memorística, apresenta vantagens tais como o enriquecimento da estrutura cognitiva do aprendiz, uma aprendizagem a médio e longo prazo e a aquisição de outras novas aprendizagens, ou a reaprendizagem (Pelizzari et al., 2002). Por sua vez, a aprendizagem mecânica ocorre através da absorção literal e não substantiva do novo material, quando este não consegue interagir com algum conhecimento já existente. O esforço nessa forma de aprendizagem é menor, porém volátil, com baixo grau de retenção na aprendizagem a médio e longo prazo. Para Ausubel (2003), esse método memorístico deve ser adotado quando o aprendente não dispõe, em sua estrutura cognitiva, de conhecimentos que facilitem uma conexão com a nova informação a ser aprendida. Em outras palavras, Ausubel defende que a aprendizagem memorística seja a primeira linha de aprendizagem de um conhecimento novo, desenlaçado, sendo este posteriormente utilizado como âncora na aprendizagem de conteúdos semelhantes.

\subsubsection{Aprendizagem por pares}

A aprendizagem por pares, proposta em Mazur (1999), prima pelo entendimento e aplicabilidade de conceitos, utilizando-se da discussão entre os alunos. Defende-se que após uma aprendizagem conceitual, os alunos devem ser guiados para o desenvolvimento de habilidades que permitam a aplicação dos seus conhecimentos em situações práticas. O ambiente educacional passa a ter uma 
característica mais dinâmica e democrática, favorecendo assim uma aprendizagem autônoma e colaborativa (Belloni \& Gomes, 2008).

Mazur aplicou sua metodologia no curso de Física da universidade de Harvard, dividindo o processo de aprendizagem em três etapas: a introdução dos conceitos, realizada através da leitura de materiais antes das aulas; a aplicação de aulas expositivas com a intenção de esclarecer as dúvidas, aprofundar a compreensão e criar confiança nos alunos; e a promoção de diálogos iniciados a partir de questões conceituais em um contexto problematizado (Pereira, 2017). Ao analisar os resultados da aplicação da metodologia, o professor Mazur observou que o nível de retenção das informações pelos alunos cresceu 40\% (A. S. P. Silva et al., 2012). Segundo Lourenço \& Machado (2017), a característica colaborativa da aprendizagem por pares promove, além das habilidades de pensamento crítico, as habilidades sociais, ao favorecer o desenvolvimento de comunidades de aprendizagem, e um fortalecimento psicológico ao centralizar o ensino no aluno.

\subsection{Desafios no Ensino de Programação}

Como relatado por Robins et al. (2003), cursos da área de Programação de Computadores são geralmente considerados difíceis e possuem altas taxas de evasão. A aquisição e desenvolvimento de conhecimentos sobre programação é um processo complexo, que envolve desde o design e compreensão de um programa à sua depuração e documentação (Robins et al., 2003). Um bom desempenho nesse campo está muitas vezes relacionado ao desenvolvimento de um pensamento computacional, o qual necessita de três pilares básicos: a abstração, relacionada com a capacidade de simplificar a realidade e representar os aspectos mais relevantes de um problema e sua solução; a análise, relacionada com a capacidade de descobrir se um problema tem ou não solução computacional, e também se pode ter algoritmo eficiente que o resolva; e a automação, relacionada com a capacidade de mecanizar as tarefas de resolução do problema usando computadores (Ribeiro et al., 2017).

Diante da complexidade de aprendizagem nesse campo, a monitoria de algoritmos e programação sendo aplicada em conjunto com metodologias de aprendizagem comprovadamente eficazes, surge como uma importante ferramenta de intervenção na tentativa de reduzir os altos índices de evasão em cursos de ensino superior. A promoção da colaboração por meio da troca de experiências, a oferta de um conteúdo estruturado e relacionado com outros conhecimentos, bem como o incentivo à discussões coletivas em que os estudantes são convidados a realizar debates sobre os assuntos recém estudados motivam os alunos em relação ao processo de aprendizagem. Para Santana et al. (2017), a motivação afeta, diretamente ou indiretamente, o desempenho do estudante em disciplinas de programação.

\section{Trabalhos Relacionados}

A Monitoria tem um importante papel no processo de ensino e aprendizagem, especialmente por ser uma das estratégias potencializadoras da aprendizagem significativa (Severino, 2009). Ao longo dos anos, diferentes trabalhos foram desenvolvidos no intuito de apresentar a experiência de projetos de monitoria na universidade em que estão implantados (Matoso, 2014; Magalhães et al., 2014; Lira et al., 2015; Amato \& Reis, 2016). 
A disciplina de Sistemas Corporais, vinculada à Escola da Saúde da Universidade Potiguar (UnP), campus Mossoró, a partir de um estudo dirigido, relatou a atividade de um estudante monitor. Este estudo concluiu que a experiência da monitoria proporcionou, dentre outras coisas, o conhecimento dos júbilos e dos contratempos da docência; a alegria por estar apoiando o processo de ensino-aprendizagem das pessoas e também a frustração pelo desestímulo de alguns estudantes que não queriam se esforçar para estudar um determinado conteúdo (Matoso, 2014). O autor identificou o aprimoramento dos conhecimentos do monitor relacionados aos conteúdos programáticos e o desenvolvimento de atividades junto com os docentes, estimulando, dessa maneira, o ingresso deste estudante na área acadêmica (Matoso, 2014).

A disciplina de Cuidados Críticos, do Bacharelado de Enfermagem da Universidade Federal de Campina Grande, ofertou monitoria como apoio aos conhecimentos práticos e teóricos. Um artigo foi gerado para descrever como foi executado o processo de monitoria da disciplina. O monitor tinha como função a criação de exemplos práticos que eram aplicados nos laboratórios, permitindo uma troca de conhecimento entre o monitor e os outros alunos (Magalhães et al., 2014). A partir destas atividades, percebeu-se que, além de proporcionar conhecimento na área acadêmica, a monitoria também pôde ajudar na execução de um processo que o aluno terá que realizar no mercado de trabalho.

A Universidade Estadual da Paraíba apresentou um estudo descritivo, do tipo relato de experiência, realizado a partir da vivência discente na monitoria das disciplinas "Anatomia Humana" e "Biologia Celular". Foi relatado que a monitoria permite que o monitor desenvolva algumas habilidades sociais e intelectuais que são importantes para o ensino (Lira et al., 2015). Outra particularidade também apresentada neste estudo foi que alguns docentes da instituição tinham problemas na sua metodologia de ensino, e que uma das possíveis causas para isto seja o fato destes docentes não terem tido a oportunidade de participar de atividades pedagógicas em seu processo de formação (Lira et al., 2015).

Uma outra questão apontada por Lira et al. (2015) é que alguns alunos podem se sentir intimidados de tirarem suas dúvidas na aula, por entenderem que a dúvida pode inferiorizar o seu conhecimento diante do professor. Neste sentido, a monitoria pode ajudá-los a sanar suas dúvidas, e diminuir a timidez e a distância, pelo fato de o monitor ser também um estudante.

Amato \& Reis (2016), considerando a monitoria como uma estratégia fundamental à aprendizagem significativa na medida em que possibilita a construção de saberes e a troca entre pares, desenvolveram um estudo de caso sobre o Programa de Monitoria do CEFET/RJ do curso de Engenharia de Produção. O objetivo principal do estudo era apresentar a percepção dos estudantes monitores em relação ao programa de monitoria. Os resultados obtidos pelos autores revelaram que a maioria dos monitores do CEFET/RJ ingressam no programa da monitoria em razão da possibilidade de exercer uma atividade extraclasse. Além disso, os autores identificaram que, embora o programa proporcione inúmeros benefícios à formação acadêmica e pessoal dos estudantes monitorados, ainda não se conseguiu popularizá-lo entre os discentes.

A Universidade Estadual do Rio de Janeiro realizou um estudo sobre o Programa de Monitoria Acadêmica realizada no seu âmbito (Assis et al., 2006). Este estudo tinha como objetivo entender as percepções dos alunos e docentes sobre o programa. O estudo fez uso de uma abordagem quantitativa descritiva, tendo uma amostra de 126 monitores e 101 professores. Os resultados apontaram que $70,7 \%$ dos monitores consideravam importante a atividade de acompa- 
nhamento das aulas práticas ministradas pelo professor. No entanto, apenas $23,8 \%$ dos monitores participaram semanalmente e 54,8\% nunca realizaram. Quanto aos monitores que não conseguiram realizar essas atividades, atribuiu-se a isso o fato de que muitos monitores eram de cursos de tempo integral, tornando mais difícil o cumprimento da carga horária do Programa. Com relação a percepção dos docentes, a atividade de orientação e preparação do monitor na execução de atividades práticas, laboratoriais e exercícios foi considerada importante por $91 \%$ dos orientadores. No entanto, somente $65 \%$ a executaram semanalmente ou esporadicamente.

Em outro trabalho, os autores desenvolveram um estudo com cinco docentes que orientam monitoria em disciplinas de psicologia na graduação (Nascimento \& Barletta, 2011). O estudo foi realizado a partir de abordagem qualitativa. Conforme apontado pelas autoras, a abordagem qualitativa foi escolhida, pelo fato de permitir o levantamento e conhecimento das percepções e comportamentos dos participantes do programa. Os resultados mostraram que os docentes decidiram ofertar a monitoria para ter um maior auxílio na disciplina, melhorar a sua operacionalidade e responder as requisições das coordenações. Destacaram, também, que as atividades realizadas pela monitoria tinham como motivo principal dar apoio aos professores e também apoio aos monitores no processo de formação à docência . No final, o estudo apontou que a maioria das atividades estavam cumprindo o primeiro objetivo em detrimento do segundo. O estudo também destacou que os docentes indicaram três características como essenciais para o monitor: domínio teórico-técnico, didática e postura profissional e ética.

O presente estudo, de maneira similar aos já mencionados, relata a experiência vivenciada no âmbito de um projeto de monitoria. No entanto, comparado àqueles, apresenta contribuições e inovações significativas. Diferentemente dos trabalhos mencionados, realizados em sua maioria em cursos da área de saúde, o nosso se desenvolve em disciplinas de cursos de Engenharia. Além disso, o nosso trabalho considera a visão dos estudantes "monitorados", dos monitores e professores, não se restringindo apenas a um ou dois atores. Também propõe-se, à luz das percepções adquiridas pelos monitores ao longo dos anos, um conjunto de estratégias pedagógicas que poderiam ser empregadas para contribuir com o aperfeiçoamento das disciplinas e, portanto, com o processo de aprendizagem dos discentes.

\section{Materiais e Métodos}

Nesta seção são apresentados os materiais e métodos que contribuíram para a execução desse trabalho. Inicialmente, é retratada uma visão geral do ambiente no qual este estudo aconteceu e, em seguida, é abordado o processo metodológico, que inclui todas as etapas utilizadas na sua condução.

\subsection{Projeto de Monitoria}

O relato de experiência descrito neste estudo se deu no âmbito do projeto "Práticas Pedagógicas que Contemplam a Formação Acadêmica e Profissional dos Estudantes de Engenharia da UEFS". O projeto busca auxiliar estudantes em disciplinas que envolvem a resolução de problemas e de raciocínio lógico matemático, bem como pensamento computacional. Em sua maioria, essas disciplinas envolvem a programação de computadores. Os monitores alocados no projeto possuem, 
entre outras atribuições, a responsabilidade de tirar dúvidas dos discentes monitorados. Vale ressaltar que o papel do monitor, em hipótese alguma, é fazer pelo estudante, mas colaborar no sentido de ajudá-lo a progredir nos seus estudos.

Considerando os estudantes dos cursos de Engenharia, observa-se a ênfase e a necessidade de que esses estudantes desenvolvam a capacidade de resolução de problemas e de raciocínio lógico matemático, habilidades desejadas e trabalhadas pelos componentes curriculares "Algoritmos e Programação I" e "MI-Algoritmos", do curso de Engenharia de Computação, e "Introdução à Ciência da Computação", dos cursos de Engenharia de Alimentos e Engenharia Civil. Neste sentido, os serviços da monitoria eram oferecidos a estudantes destes cursos. De maneira especial, em razão de apresentar conceitos básicos relacionados à computação, bem como por priorizar o desenvolvimento do pensamento computacional e do raciocínio lógico matemático dos estudantes, o componente curricular "Informática Aplicada" dos cursos de Química e Agronomia também fez parte do rol de disciplinas apoiadas pela monitoria.

Para o desenvolvimento das atividades da monitoria, 12h semanais eram reservadas, preferencialmente em turnos opostos aos das aulas, a fim de atingir a maioria dos estudantes. Ao monitor era atribuído o papel de acompanhar os estudantes em alguns momentos/horários no laboratório, ajudando-os a compreender e utilizar o ambiente de desenvolvimento, a linguagem de programação e os conteúdos estudados, em especial, nas práticas das disciplinas envolvidas. Para tanto, ao longo dos anos da monitoria, diferentes estratégias foram empregadas a fim de contemplar esse aspecto, entre as principais estão:

- Encontros presenciais com os estudantes: Horários semanais eram reservados para encontros com os discentes. Qualquer aluno monitorado poderia participar desses encontros para tratar sobre as suas dúvidas. As dúvidas eram resolvidas por meio de exemplos práticos, a partir da utilização de questões semelhantes às que eram mencionadas pelos discentes, teste de mesa ou a partir de representações gráficas para o melhor entendimento da estrutura, este último caso sendo mais utilizado na explicação de estruturas de dados como listas encadeadas e matrizes.

- Atendimento utilizando recursos digitais: Além dos encontros presenciais da monitoria, os estudantes monitorados tinham a oportunidade de tirar dúvidas com os monitores por outros meios de comunicação, como e-mail, WhatsApp, Discord, entre outros. Essas ferramentas eram úteis principalmente para àqueles estudantes que não residiam próximo da Universidade, o que acrescentaria mais um empecilho em buscar a monitoria. Além disso, poderia ocorrer incompatibilidade do horário estabelecido pelo monitor para atendimento presencial com aqueles de disponibilidade do discente. Assim, esses recursos se tornavam uma alternativa para estudantes que se enquadravam nesse perfil. Vale salientar que, durante a pandemia, os atendimentos da monitoria foram realizados de forma remota, utilizando exclusivamente recursos digitais.

- Participação em aulas de exercícios das disciplinas teóricas: Em determinado período, as disciplinas teóricas, com as quais a monitora colaborava, realizavam aulas de exercícios, notadamente antes de avaliações. Em algumas oportunidades, os monitores também participaram dessas aulas, ajudando aqueles estudantes que apresentavam dúvidas. Era um momento de construção colaborativa (i.e. professores, estudantes e monitores) de soluções para os problemas/exercícios apresentados. 
- Produção de materiais didáticos: Além dos encontros presenciais e a utilização de outros recursos para aprimorar o serviço prestado, os monitores também desenvolviam materiais pedagógicos para apoiar os estudantes. Foram produzidas listas de exercícios, que eram então disponibilizadas no site vinculado à monitoria ${ }^{1}$, assim como vídeo aulas e apostilas das temáticas vistas em aula (e.g. operadores lógicos e aritméticos, estruturas condicionais, estruturas de repetição, estruturas de dados, funções, entre outras).

- Aplicação de minicursos preparatórios: Durante a semana de integração do curso de Engenharia de Computação, que acontece geralmente na primeira semana de aula, os estudantes monitores aplicam um minicurso abordando assuntos relacionados à lógica, algoritmos e programação. Tais minicursos têm como objetivo promover, nos estudantes novatos, o desenvolvimento de um conhecimento inicial que posteriormente favoreça uma aprendizagem significativa. Os minicursos aplicados são comumente abordados em três etapas: (1) Fluxograma Humano, focado na aprendizagem de algoritmos por meio da computação desplugada; (2) Jogo de Lógica, que trata da aprendizagem por meio da colaboração e da divisão de tarefas, e; (3) Introdução a Programação, transformando algoritmos em códigos executáveis por meios de comandos básicos da linguagem de programação $\mathrm{C}$ e/ou Python.

As atividades mencionadas tencionavam contribuir no processo de aprendizagem dos estudantes "monitorados", assim como na inserção do monitor à prática docente. Durante a aplicação dessas atividades e dos atendimentos realizados, os monitores têm a oportunidade de realizar observações e adquirir novas percepções da prática docente, especialmente relacionadas ao ensino de Programação de Computadores. É neste contexto, sob observações e percepções, que esse trabalho se desenvolve. Mais detalhes acerca do processo metodológico são apresentados em sequência.

\subsection{Processo Metodológico}

A presente pesquisa trata-se de um estudo descritivo, do tipo relato de experiência, que visa descrever as vivências de estudantes "monitorados", monitores e professores, enquanto participantes de um projeto de monitoria. Metodologicamente, relatos de experiências permitem realizar a descrição de experiências vivenciadas, de natureza qualitativa, tendo em vista que evidenciam aspectos subjetivos do ser humano (Gil, 2002; E. L. Silva \& Menezes, 2001). Neste sentido, por meio do relato de experiência, é possível suscitar novos debates e reflexões sobre uma determinada temática.

Desde a sua implantação, em 2016, até o presente momento, a monitoria já contou com a participação de 9 estudantes monitores, todos discentes do curso de Engenharia de Computação. O fato de todos os monitores serem oriundos do curso de Engenharia de Computação justifica-se por conta da natureza das disciplinas contempladas pelo projeto, as quais em geral requerem competências de programação de computadores, com ênfase na resolução de problemas. Assim, uma das vertentes deste estudo foi realizado com base nas experiências desses estudantes monitores, com relação às atividades didático-pedagógicas efetuadas no período que estiveram na condição de monitor. Com relação aos estudantes "monitorados", participaram desse estudo apenas os estudantes das disciplinas Algoritmos e Lógica de Programação I e MI algoritmos do semestre letivo remoto 2020.1 da UEFS, tendo em vista que neste semestre a monitoria atendeu exclusivamente a

\footnotetext{
${ }^{1} \mathrm{http}: / /$ monitoriaalgoritmos.uefs.br/
} 
essas duas disciplinas. $\mathrm{O}$ fato da disciplina ter sido ofertada de forma remota acrescenta uma outra dimensão que pode ser analisada, ou seja, a percepção dos estudantes quanto ao ensino remoto das disciplinas mencionadas. Com relação aos professores, participaram deste estudo aqueles professores que ministraram, mesmo que por um curto período, alguma disciplina vinculada à monitoria.

A condução deste estudo seguiu basicamente 5 etapas, indicadas na Figura 1. Inicialmente foi definida a temática que seria abordada, com auxilio dos três últimos monitores envolvidos com o projeto, os quais figuram entre os autores deste trabalho. Em uma outra etapa foi realizado um levantamento bibliográfico, no intuito de encontrar os principais conteúdos associados à monitoria, bem como trabalhos semelhantes ao abordado neste artigo. Em seguida, realizou-se a elaboração dos questionários ${ }^{234}$ para o levantamento de dados, composto tanto por questões abertas quanto fechadas. Os questionários foram elaborados de modo a capturar algumas dimensões delineadas pelos autores. Por exemplo, no questionário dos estudantes monitores, buscou-se verificar dimensões como: Motivos que os levaram a participar da monitoria; Qualidade da experiência vivenciada no projeto; Impacto da monitoria em suas habilidades/competências; Abrangência da monitoria; Dificuldades enfrentadas; Lições aprendidas; e estratégias para melhorar o serviço prestado.

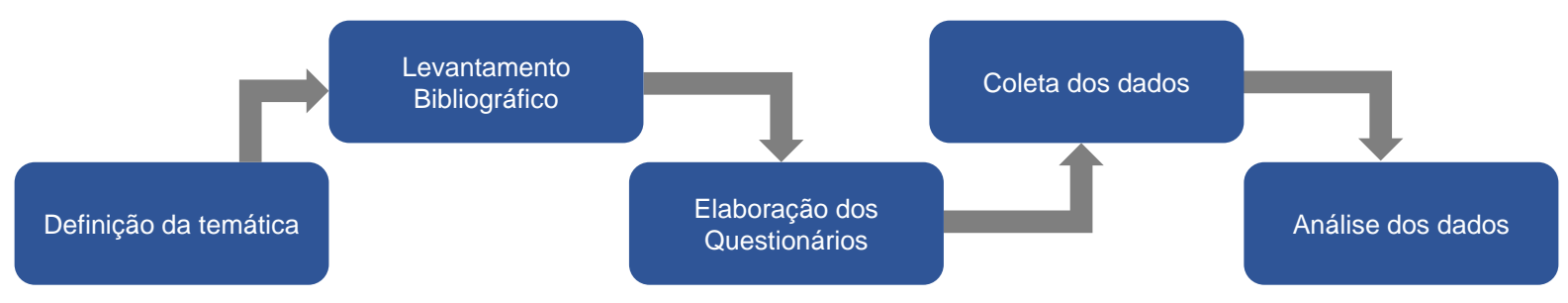

Figura 1: Workflow de desenvolvimento do estudo.

Em um outro momento, aplicaram-se os questionários com os envolvidos neste estudo. De modo geral, os questionários desenvolvidos tinham como objetivo permitir o levantamento e conhecimento das percepções e comportamentos dos participantes do programa. Especialmente em relação aos monitores, o questionário buscava avaliar também a contribuição da monitoria para o aprimoramento pessoal e técnico desses estudantes. Além disso, buscava-se fazer um levantamento das principais lições aprendidas, incluindo as dificuldades percebidas e as habilidades adquiridas durante o período que participaram do projeto da monitoria. Ressalta-se que todos os questionários foram respondidos diretamente da plataforma Google Forms ${ }^{5}$. Especificamente, em relação aos estudantes "monitorados" e professores, os questionários foram respondidos no final do semestre em vigor.

Por fim, na quinta etapa, após os participantes reponderem os questionários, conduziu-se a análise dos dados. Vale salientar que apesar da utilização de questionários para a coleta de dados, esse estudo ainda assim mantém um caráter qualitativo, pois está centrado nos aspectos subjetivos (Günther, 2006).

\footnotetext{
${ }^{2}$ Questionário estudantes monitores: https://forms.gle/XJ29Sw8pqDmH8t7F6

${ }^{3}$ Questionário estudantes "monitorados": https://forms.gle/x2H3YAnvh5kin83x5

${ }^{4}$ Questionário professores: https://forms.gle/9Lw1ZDh85HoPTmsq9

${ }^{5}$ https://www.google.com/forms/about/
} 


\section{Resultados e Discussão}

Os resultados estão separados em três seções principais. Na primeira seção, realiza-se uma análise dos resultados obtidos por meio dos questionários, considerando a visão dos monitores. Enquanto isso, a segunda seção considera a visão dos estudantes "monitorados". Por fim, a última seção retrata os resultados sob a ótica dos professores.

\subsection{Visão dos monitores}

\subsubsection{Experiência dos monitores}

A inscrição no projeto de monitoria pode estar associada a diferentes motivações, sejam de cunho intrínseco ou extrínseco. Considera-se como motivação intrínseca aquela na qual o individuo busca, naturalmente, novidades e desafios, não sendo necessárias pressões externas ou prêmios pelo cumprimento da tarefa, uma vez que a participação nessa é a recompensa principal. A motivação extrínseca, por sua vez, é aquela vinculada a algo externo à tarefa ou atividade, como, por exemplo, para a obtenção de recompensas materiais, sociais ou de reconhecimento (Martinelli \& Bartholomeu, 2007). A Figura 2 exibe os principais motivos que levaram os monitores a participarem do projeto de monitoria. Como pode ser observado, os principais motivos indicados pelos estudantes foram "Contribuir significativamente com o processo de aprendizagem de outros estudantes" (100\%), o "Interesse em ingressar na vida acadêmica/docente" (88,7\%) e "Aprimorar minhas habilidades relacionadas à Programação de Computadores" $(66,7 \%)$. De modo geral, as escolhas realizadas pelos estudantes corroboram com os objetivos que sustentam a criação de projetos de monitoria. Afinal, entre vários objetivos que justificam a criação da monitoria está a busca por ser uma ferramenta de importância no processo de aprendizagem dos estudantes, além de ser um passo inicial de iniciação à docência (Assis et al., 2006).

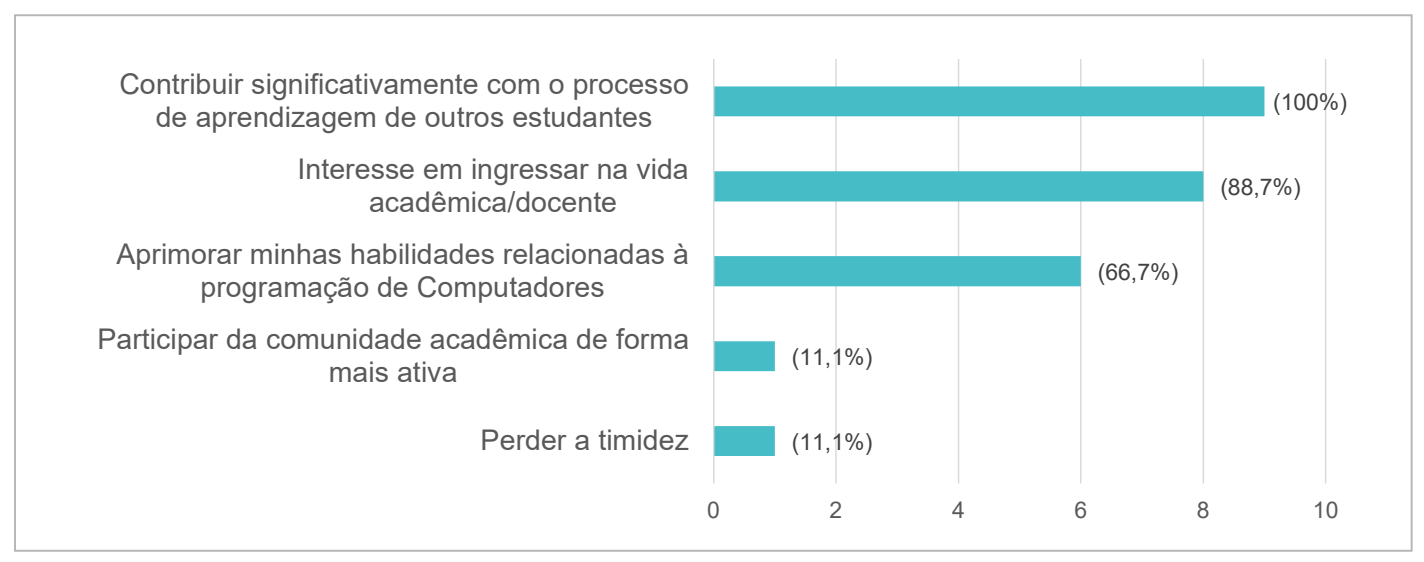

Figura 2: Motivos principais de ingresso na monitoria.

A Figura 3 ilustra como foi o grau de experiência do monitor, considerando o período deste nesta condição. Observou-se que, em sua grande maioria, os monitores indicaram a experiência como Muito Bom (56\%). Outros indicaram como sendo Excelente (33\%) e Bom (11\%). Ressaltase que nenhum dos monitores que respondeu o questionário apontou a experiência como Razoável 
ou até mesmo Ruim. Esse resultado mostra que a monitoria tem sido uma experiência positiva para os discentes que dela participam, mesmo diante de dificuldades inerentes ao processo.

Com relação aos cursos de Engenharia, o Conselho Nacional de Educação (CNE) prevê que o engenheiro dos cursos de graduação deve ter "formação generalista, humanista, crítica e reflexiva, capacitado a absorver e desenvolver novas tecnologias, com atuação crítica e criativa na identificação e resolução de problemas" (CNE, 2002). Diante disso, buscou-se avaliar algumas dessas dimensões, como forma de verificar o impacto da monitoria em alguns desses aspectos. Assim, na Figura 4, exibe-se uma relação das habilidades/competências aprimoradas a partir da participação na monitoria. Conforme indicado pelos participantes, características como Metodologia de ensino (100\%), Relação interpessoal $(88,9 \%)$, Empatia $(77,8 \%)$, Oralidade $(77,8 \%)$ e Responsabilidade $(66,7 \%)$ tiveram um impacto positivo. De modo geral, percebe-se que a monitoria contribuiu com o processo de formação dos discentes para se alcançar alguns dos objetivos definidos pelo CNE, tão importantes para os engenheiros.

A monitoria, em vários aspectos, pode contribuir na formação dos estudantes. O resultado revelado na Figura 4 ratifica a importância de uma formação ampla para os estudantes de engenharia. Afinal, o processo de formação e qualificação do engenheiro, de maneira similar a outros profissionais, requer um arcabouço de conhecimento diferenciado, aliado à capacidade de análise em profundidade da realidade política, social, cultural, entre outras habilidades exigidas para viver e conviver no mundo moderno (Cordeiro et al., 2009). Vale ressaltar que esse processo formativo deve levar em conta as necessidades da nação e o bem-estar da sociedade.

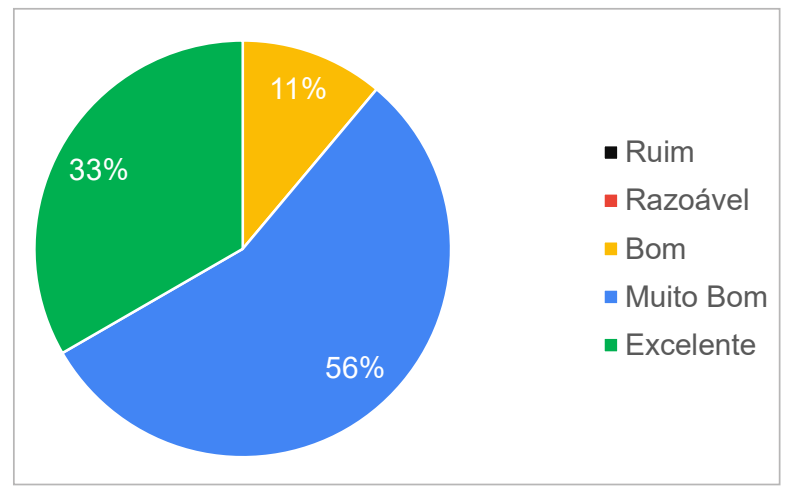

Figura 3: Experiência como monitor no projeto da monitoria.

\subsubsection{Percepções e dificuldades encontradas na monitoria}

A monitoria pode contribuir positivamente em diferentes aspectos para o monitor, sejam pessoais e/ou intelectuais. A relação de troca de conhecimentos proporcionada pela monitoria se revela importante para o desenvolvimento interpessoal dos envolvidos.

Analisando o conteúdo do questionário, encontram-se relatos de como a monitoria impactou em habilidades interpessoais, especialmente com relação à habilidade de se comunicar com as pessoas, uma vez que as atividades da monitoria exigem constante exposição. Alguns dos monitores perceberam a importância do ensino no processo de aprendizagem, isto é, aprender ensinando. Todos esses aspectos de alguma forma estão relacionados com princípios defendidos pela aprendi- 
zagem colaborativa e em pares, na medida em que põem os estudantes como os principais agentes do seu aprendizado, primando pela autonomia, responsabilidade e troca de experiência entre os envolvidos (Mazur, 1999; Cunha Júnior, 2017). De maneira particular, também corrobora com o saudoso Paulo Freire, quando ele afirma que "Quem ensina aprende ao ensinar e quem aprende ensina ao aprender" (Freire, 2011). Isso revela a importância da monitoria no processo de ensinoaprendizagem dos discentes, pautado em uma educação que os põem como protagonistas do seu aprendizado. Outros mencionaram a importância de introduzir aplicações de conteúdos de forma lúdica para explicar assuntos potencialmente complexos.



Figura 4: Habilidades/competências aprimoradas a partir da participação na monitoria.

Considerando as dificuldades encontradas enquanto monitores do projeto, cinco, dos nove respondentes, relataram ter percebido uma resistência dos alunos em procurar a monitoria. Entre as possíveis causas foram citados: problemas relacionados ao transporte; dificuldade de acesso à universidade em horários fora das aulas; falta de tempo devido a outras atividades acadêmicas; e a estranheza à ideia de monitoria.

Ainda considerando as dificuldades, quatro dos monitores mencionaram dificuldades relacionadas aos laboratórios e salas utilizadas. Entre os problemas citados estão: a dificuldade de acesso aos locais da atividade; a falta de recursos, tais como quadros, pincéis, computadores e internet; e o tamanho dos espaços utilizados. Estas questões podem acabar afetando o desenvolvimento do projeto da monitoria, tendo em vista o desgaste que isso pode gerar.

Com relação aos alunos monitorados, relatos individuais mencionam a resistência dos alunos à aplicação de metodologias colaborativas de aprendizagem; falta de gerenciamento do tempo para poder participar dos encontros da monitoria; falta de motivação em relação às atividades propostas; dificuldades em conciliar as atividades acadêmicas com as atividades de monitoria; e uso da monitoria para resolver de forma fácil as atividades avaliativas passadas pelos professores em sala. 


\subsubsection{Lições aprendidas}

O presente trabalho se configura, fundamentalmente, como um relato de experiência. Neste sentido, registram-se algumas lições mais importantes aprendidas pelos monitores ao longo dos anos com o projeto de monitoria.

Aprofundamento do conhecimento. A experiência com a monitoria proporcionou muitos ganhos pessoais para os monitores, como empatia, oralidade e relação interpessoal. Além desses aspectos, a monitoria pôde contribuir com o aprofundamento dos conteúdos de computação que eram abordados, uma vez que era necessário fazer uma revisão do conteúdo, visando a oferta de um atendimento cada vez mais qualificado aos discentes monitorados. Além disso, como os monitores geralmente são estudantes que já estão um pouco mais avançados no curso, rever o conteúdo depois de já ter cursado disciplinas mais avançadas do curso permitiu enxergar o tópico por outro ângulo e compreender melhor o seu funcionamento.

Aprimoramento de competências/habilidades interpessoais. A experiência da monitoria proporcionou o aperfeiçoamento de competências interpessoais, tão importantes nos dias atuais. Habilidade como o processo de ensinar, especialmente no que diz respeito à organização e à estruturação dos conteúdos e na forma de repassar o conhecimento, foi uma delas. Ademais, houve um aprimoramento em relação à capacidade de ouvir, de desenvolver o raciocínio em uma conversa e a construção de laços de amizade. Também houve um avanço em habilidades como a oratória e a capacidade de trabalhar em equipe, assim como o desenvolvimento da inteligência emocional.

Aprendizagem colaborativa. A partir da experiência da monitoria, percebeu-se como a aprendizagem colaborativa é um tema atual e de significativa importância para os professores e estudantes, sendo um dos fatores mais presentes na monitoria, especialmente quando se fala em aprendizado em pares. No entanto, percebeu-se também que esse tipo de aprendizagem ainda apresenta certa resistência por parte dos estudantes monitorados, possivelmente devido a fatores como timidez e dificuldade de compartilhar o conhecimento (medo de perda de controle). No entanto, apesar da presença dessas dificuldades e resistências em sua aplicação, utilizar a aprendizagem colaborativa resulta em bons resultados, especialmente se associada com estratégias lúdicas, uma vez que se aproveita dos melhores aspectos que ambas estratégias podem promover. Ao aplicar a aprendizagem colaborativa junto a estratégias lúdicas, pode-se promover uma sinergia, que inclui um esforço contínuo de colaboração entre os alunos, potencializando a troca de experiências e consequente aprendizagem (Cunha Júnior, 2017). As atividades lúdicas podem motivar enquanto divertem e aumentar a capacidade de retenção do que é ensinado, a exemplo de jogos educacionais (Tarouco et al., 2004).

Ensino personalizado. Cada estudante possui uma forma diferenciada de lidar com a Universidade, seja em razão de experiências pessoais anteriores ou, até mesmo, pelas fragilidades na escolaridade anterior. Em função dessas características, junto às dificuldades de interpretação de problemas e de raciocínio lógico matemático, muitas vezes fez-se necessário adaptar o discurso para individualizar o atendimento, conforme o perfil do estudante.

Observou-se a importância de personalizar o ensino (e.g. uso de exemplos contextualizados, escuta ativa/passiva, execução de código passo a passo, uso frequente de analogias, exercícios com níveis de dificuldades intercalados, uso do quadro para o estudante monitorado explicar algum conteúdo, sessão de brainstorm, entre outras.), tendo em vista o grau de experiência de cada 
estudante. Tudo isso, em certa medida, tem forte relação com a ideia de aprendizagem significativa defendida por Ausubel, especialmente com relação a construção espontânea de novos conceitos com base em seu conhecimento prévio, incorporando inúmeras vantagens quando comparada com a aprendizagem mecânica, ou memorística (Pelizzari et al., 2002).

Motivação. Muitos dos alunos que procuraram a monitoria relatam situações pessoais que sugerem a presença de problemas motivacionais, o que pode acabar afetando o seu rendimento acadêmico (Santana et al., 2017), ocasionando outros problemas que comumente afetam os cursos de engenharia, como reprovações e evasão (Reis et al., 2012). Neste sentido, percebeu-se que o monitor, além de ensinar assuntos técnicos de programação, também deve estar atento aos aspectos motivacionais dos estudantes para que, na medida do possível, tente motivá-los, inserindo práticas pedagógicas que despertem a motivação, o engajamento e aumentem a confiança desses estudantes. Aqui vale ressaltar a relação existente entre a personalização do conteúdo com a motivação. A busca pela personalização do ensino é um dos caminhos que pode ser trilhado em uma tentativa de despertar a motivação dos estudantes monitorados, especialmente a motivação intrínseca.

Dificuldade com conceitos abstratos de computação. A vivência direta com os estudantes permitiu perceber que determinados conceitos, potencialmente abstratos de programação de computadores, acabam gerando inúmeras dúvidas nos alunos. Em geral, conceitos como estruturas matriciais, alocação de memória, métodos de ordenação e recursividades geraram dúvidas recorrentes nos discentes.

\subsubsection{Intervenções pedagógicas}

Ao longo do desenvolvimento da monitoria, diferentes problemas foram percebidos como as dificuldades já mencionadas. Para minimizar esses e outros problemas, algumas estratégias intervencionistas podem ser empregadas, como por exemplo:

- Inclusão de atividades lúdicas: Atividades lúdicas poderiam ser utilizadas de forma mais efetiva, especialmente para explicar aqueles conceitos considerados potencialmente abstratos como estrutura de repetição, estruturas matriciais, alocação de memória, métodos de ordenação e recursividades. Para apoiar essa intervenção, ambientes como o scratch e o code.org poderiam ser utilizados. Além disso, a computação desplugada também poderia ser empregada em conjunto com outras estratégias.

- Intensificar a utilização de metodologias ativas de ensino: Embora a monitoria em si já possua aspectos de metodologias ativas, como a aprendizagem em pares, é preciso intensificar a utilização de estratégias que promovam o protagonismo do estudante em seu processo de aprendizagem. Deste modo, com o apoio dos professores das disciplinas contempladas pela monitoria, poderiam ser utilizadas estratégias como sala de aula invertida, gamificação e pequenos projetos para serem resolvidos em grupo na sala de aula. Além disso, quando possível, convidar os estudantes para explicar alguns conteúdos após estudo anterior. Com relação a esta última parte, esse convite poderia ser realizado de forma aleatória, por meio de sorteio por exemplo, de modo que todos os estudantes se preparassem para executar tal atividade. 
- Inserir atividades que despertem motivação: Como indicado em Santana et al. (2017), a motivação afeta, direta ou indiretamente, o desempenho do estudante, com consequências explícitas no processo de aprendizagem. Neste sentido, uma alternativa que poderia ser utilizada para minimizar ou, até mesmo, superar este problema é partir da incorporação de estratégias que despertem a motivação desses estudantes, tais como: utilização de jogos; promover aulas interativas; incentivar o aluno a chegar a resposta sem entregar a resposta de imediato (que já vem sendo feito); atividades com objetivos bem definidos, ou seja, objetivos claros e divididos em etapas menores; e atividades que permitam aos estudantes perceberem a utilidade do assunto, ou seja, relacionado a uma aplicação prática de conhecimento dos discentes (Santana et al., 2017) ou a conhecimentos prévios e contextualizados. Para tanto, poderia ser empregado o ensino de programação em Python com mídias, utilizando áudio e imagens por exemplo, a partir do ambiente de desenvolvimento JES (Guzdial \& Ericson, 2009), do inglês Jython Environment for Students.

As intervenções supracitadas podem ser incorporadas em diferentes ambientes, sejam nas aulas das disciplinas apoiadas pela monitoria, como nos encontros individualizados realizados pelo monitor. Para esses momentos, seria importante priorizar aqueles assuntos considerados mais difíceis de aprender, tomando como base o que é dito pela literatura, assim como a própria experiência dos professores que ministram as aulas, cujo nível de experiência permite perceber as maiores dificuldades dos discentes e, sobretudo, os relatos e experiências prévias dos estudantes monitorados.

\subsection{Visão dos estudantes}

Participaram desse estudo, 33 estudantes matriculados nas disciplinas Algoritmos e Programação I e MI-Algoritmos, ofertadas de forma remota, em decorrência da COVID-19. Dos respondentes, $67 \%$ tinham entre 18 e 20 anos de idade. Os outros 33\% restantes tinham entre 21 e 24 anos. Com relação ao sexo biológico informado, $82 \%$ declararam ser do sexo masculino e $18 \%$ do sexo feminino. Cerca de $36 \%$ dos estudantes indicaram que antes de entrar no curso de engenharia da computação já tiveram aula de alguma linguagem de programação. Aqui vale destacar que alguns desses estudantes tiveram contato com alguma linguagem de programação, na verdade, já quando estavam matriculados no curso, por meio de oficinas que antecedem o início das aulas. Deste modo, o percentual de estudantes que de fato tiveram contato com programação antes de entrar no curso, possivelmente, é menor do que o extraído do questionário. De modo geral, nota-se que a turma é composta, em sua maioria, por pessoas bem jovens e por homens, e que apenas um número bem reduzido já conhecia alguma linguagem de programação.

Na Figura 5 é apresentada a interação dos alunos com a monitoria, bem como o nível de dedicação destes em relação ao processo de aprendizagem. A análise dos dados sugere que apesar de os alunos acreditarem na importância da disciplina $(96,97 \%)$, terem a priorizado $(66,66 \%)$, saberem da existência da monitoria $(75,76 \%)$ e até a indicarem aos seus colegas $(69,70 \%)$, poucos sentem a necessidade de procurar o monitor $(30,30 \%)$ e ainda menos realmente participam dos encontros $(18,18 \%)$. Quanto à justificativa da não participação na monitoria, uma possibilidade seria em relação aos horários. Sobre essa temática, duas questões foram feitas, uma em relação à compatibilidade de horários e outra em relação à organização da agenda para a acomodação da monitoria. O questionamento quanto à compatibilidade de horários foi o que mais 
obteve respostas neutras $(57,57 \%)$, no mais, a porcentagem dos que concordaram que os horários disponibilizados favoreceram o acesso aos monitores foi consideravelmente maior $(30,30 \%$ contra $12,12 \%$ ). Quanto à organização da agenda de maneira que sobrasse tempo para participarem da monitoria, a maioria dos alunos relatou não terem feito $(66,70 \%$ contra $3,03 \%$, e $27,27 \%$ neutros).

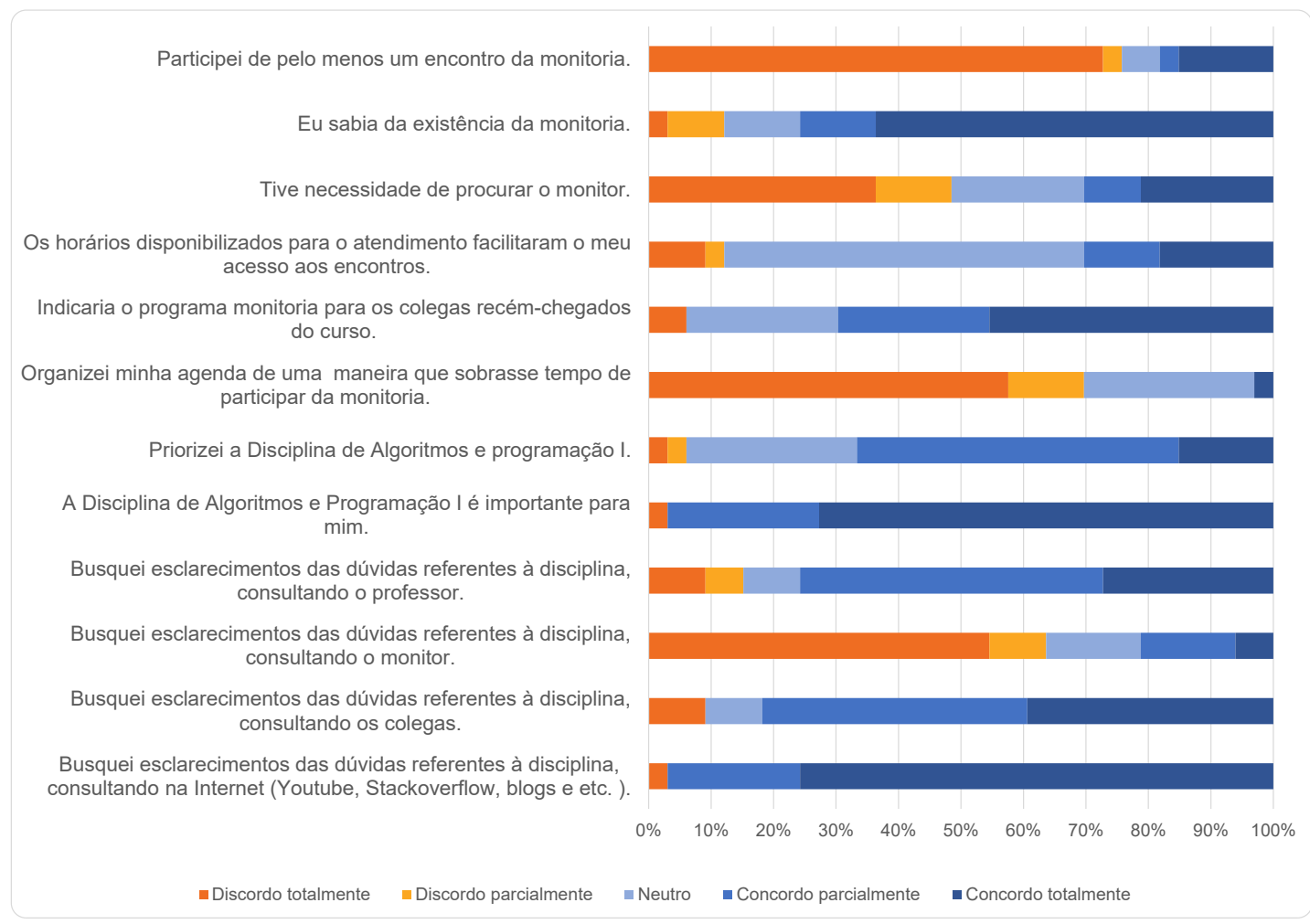

Figura 5: Interatividades e dedicação dos alunos com a monitoria.

A Figura 5 ainda nos fornece informações sobre a dedicação dos alunos à disciplina. A análise dos dados sugere que a principal fonte de esclarecimento das dúvidas é a internet $(96,97 \%)$, seguida dos colegas $(81,82 \%)$, do professor $(75,76 \%)$ e, por fim, dos monitores (apenas $21,21 \%$ ). A utilização da internet como um meio para o esclarecimento de dúvidas corrobora com o que foi relatado por Diesel et al. (2018), quando afirmam que o uso das tecnologias digitais estimulam a autonomia do estudante. Nesse contexto, acreditando que os materiais didáticos, físicos ou digitais sejam a primeira fonte de conhecimento para o esclarecimento de dúvidas, foi enfatizada a importância de um material potencialmente relacionável com a estrutura cognitiva dos alunos, favorecendo assim uma aprendizagem significativa (J. B. Silva, 2020). Os resultados mostram ainda a importância da aplicação de atividades colaborativas, focadas na troca de experiências entre os alunos.

Os questionamentos apresentados na Figura 6 buscaram entender o posicionamento dos alunos em relação às estratégias que podem ser adotadas para incentivar a participação na monitoria. Apenas 3,03\% dos alunos discordaram sobre a aplicação de novas estratégias. No geral, com exceção de tornar a monitoria obrigatória (75,76\% discordam sobre essa possibilidade), os alunos foram favoráveis à aplicação de novas abordagens: 93,94\% concordam em criar grupos com os estudantes da disciplina, utilizando ferramentas como Whatsapp, Telegram e outros; $66,66 \%$ con- 
cordam em publicações semanais com dicas de programação na página do instagram da monitoria; e $60,61 \%$ concordam em oferecer recompensas pela participação na monitoria.



Figura 6: Posicionamento dos alunos sobre estratégias que podem ser adotadas para incentivar a participação na monitoria.

Na Figura 7 é exibido o resultado da percepção dos estudantes em relação à profissão envolvendo Computação e as disciplinas Algoritmos e Programação I e MI de Algoritmos. Observou-se que, em sua grande maioria, os estudantes conseguiram perceber como a programação pode ser aplicada para resolver problemas reais (Concordo totalmente, 60\%). Além disso, cerca de 52\% dos estudantes concordam que os conteúdos abordados na disciplina têm relação com seu cotidiano, enquanto $36 \%$ concordaram parcialmente. A disciplina também conseguiu alcançar as expectativas e objetivos dos discentes (Concordo totalmente, 70\%). Isso evidencia que os estudantes chegam com um entendimento básico do que vai ser requirido deles no curso escolhido e, como pode ser percebido, a disciplina conseguiu proporcionar o esperado. De um modo ou de outro, todos esses aspectos destacados sugerem que as disciplinas contempladas pelo projeto de monitoria têm cumprido o seu papel na formação desses estudantes. No entanto, é importante destacar que alguns estudantes ainda não possuem uma opinião formada quanto a isso, que se revela ao observarmos que ainda existe um percentual de estudantes que preferiram manter a neutralidade com relação às declarações.

Ainda considerando o resultado expresso pela Figura 7, pode-se observar qual a percepção dos estudantes em relação às profissões que envolvem computação, como é o caso do curso engenharia da computação. Considerada como uma habilidade difícil de ser aprendida, os nossos resultados indicam que a maioria dos estudantes não acha programação de computadores difícil (Discordo totalmente e discordo parcialmente, 52\% ). Apenas 2 estudantes, ou seja, 0,6\% dos respondentes consideram programação de computadores difícil. No entanto, é importante observar que um número alto de estudantes se mantiveram neutros (30\%) quanto a esse aspecto. Aqui vale destacar também que a linguagem de programação utilizada foi a linguagem Python, a qual 
comumente é considerada uma linguagem mais simples de ser aprendida. Além disso, o fato de alguns dos estudantes terem tido contato com a linguagem de programação Python antes do início das aulas pode ter influenciado nesse resultado. Na Figura 7, também é possível perceber que os estudantes acham a profissão divertida (Concordo totalmente, 61\%), demonstrando que os discentes, pelo o entendimento que possuem da profissão, têm afinidade com as habilidades que são requiridas por ela.

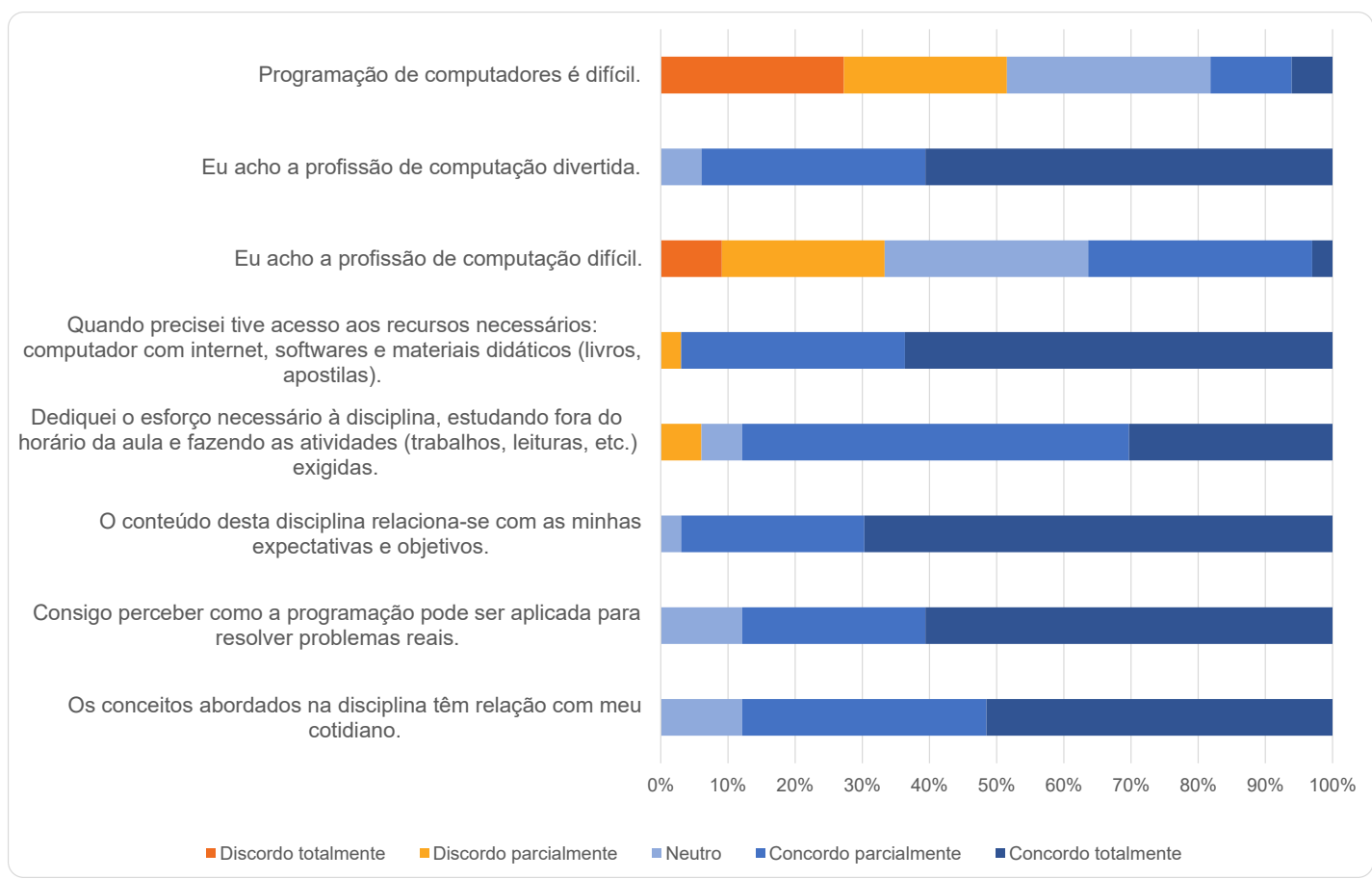

Figura 7: Percepção dos estudantes em relação a profissão envolvendo Computação e as disciplinas Algoritmos e Programação I e MI de Algoritmos.

A Figura 8 retrata a visão dos estudantes com relação às aulas das disciplinas. De modo geral, os estudantes mostraram ser dinâmicos e abertos à colaboração. Por exemplo, eles indicaram que compartilham e discutem resultados e conclusões com os colegas (Concordo parcialmente e Concordo totalmente, 67\%); têm facilidade em compartilhar seus conhecimentos (Concordo parcialmente e Concordo totalmente, 61\%); se sentem à vontade para participar das aulas, fazendo perguntas e/ou elaborando respostas (Concordo parcialmente e Concordo totalmente, 64\%) e se reuniram virtualmente com os colegas para discutir sobre conteúdos vistos na disciplina (Concordo parcialmente e Concordo totalmente, $58 \%$ ).

O período remoto, decorrido da pandemia, tem imposto inúmeros limites para a sociedade, inclusive para a educação. O resultado expresso na Figura 8, mesmo que indiretamente, ilustra esse impacto. Observa-se que, embora a tecnologia seja uma aliada para a continuidade das atividades nesse momento difícil, alguns estudantes acreditam que as aulas on-line não favoreceram o seu entendimento (Discordam parcialmente e Discordam totalmente, 36\%). Além disso, alguns dos discentes também indicaram que não se reuniram virtualmente com os colegas para discutir sobre conteúdos vistos na disciplina (Discordam parcialmente e Discordam totalmente, 36\%). O fato desses estudantes nunca terem se reunido presencialmente pode ter influenciado nisso, tendo em vista que acaba se criando uma barreira social entre eles, dependendo da sua personalidade 
e da forma como lida com o desconhecido. Neste sentido, mesmo sabendo que este período de aulas remotas seja temporário, é importante utilizar recursos que possibilitem romper essas barreiras, a fim de proporcionar uma maior interatividade entre os discentes, utilizando ferramentas diversas, tais como o Moodle e o Canvas. Alguns estudos, como Abegg et al. (2010) e Figuerêdo et al. (2017), descrevem algumas experiências de como essas ferramentas podem ser utilizadas para proporcionar uma aprendizagem colaborativa.

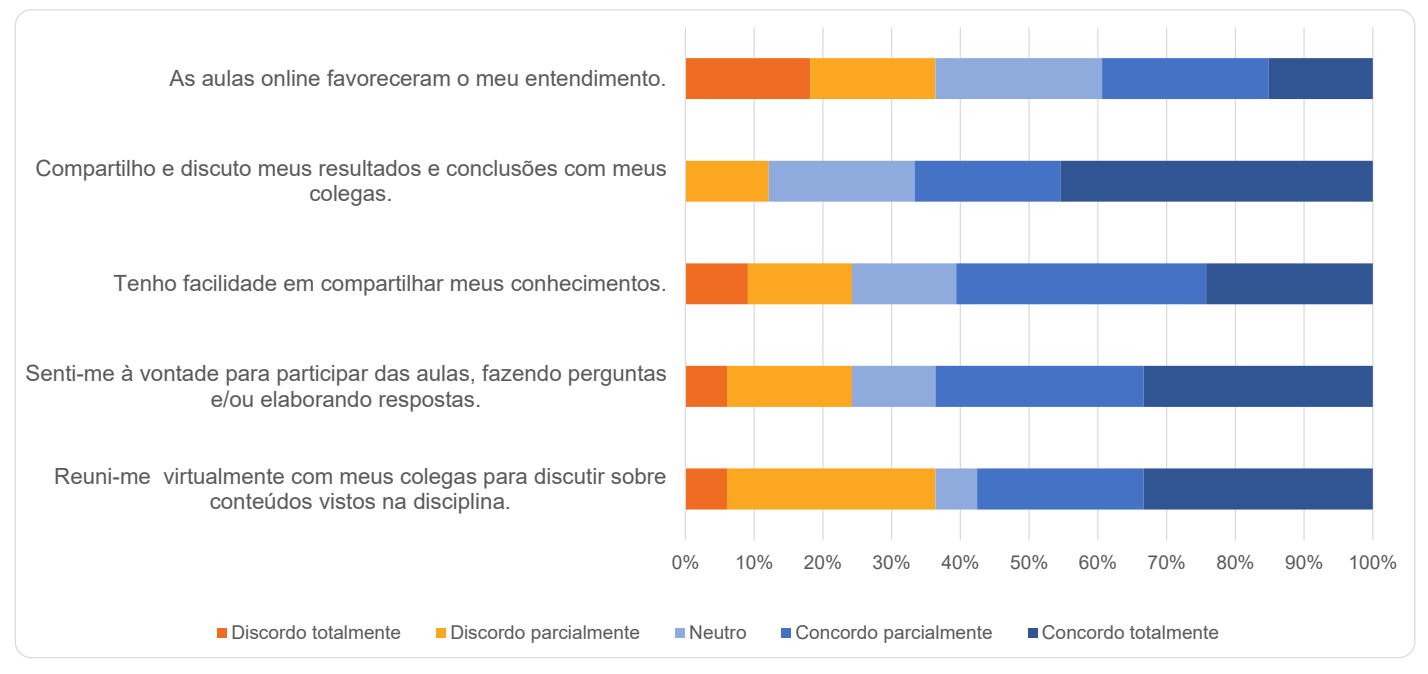

Figura 8: Visão dos estudantes com relação às aulas das disciplinas.

Em outro momento, foi perguntado aos estudantes quais conceitos relacionados à programação de computadores eles tiveram mais dificuldade ao longo do semestre. O resultado obtido pode ser visualizado na Figura 9. Como pode ser observado, os conceitos de recursividade, métodos de ordenação e busca (sequencial e binária) foram os conceitos que eles apresentaram mais dificuldade em compreender. Assim, este resultado indica a necessidade do professor e do monitor direcionar uma atenção especial a esses tópicos quando forem abordados em aula. Aqui vale salientar que os conceitos de estruturas condicionais, listas e tuplas também constavam no rol de opções que os estudantes poderiam selecionar. No entanto, nenhum dos estudantes selecionou essas opções, indicando que não houve uma dificuldade expressiva em compreender esses conteúdos. Vale destacar que esse resultado expresso na Figura 9 corrobora com a visão dos monitores em relação aos conceitos que os estudantes, em geral, têm mais dificuldades, os quais foram apresentados na Seção 5.1.3.

\subsection{Visão dos professores}

Ao se considerar um relato de experiência, é importante que haja uma amplitude de visões com relação ao tema posto. Neste sentido, a visão dos profissionais que estiveram na condição de professor em alguma disciplina contemplada pelo projeto de monitoria se mostra essencial. Em nosso trabalho, 12 professores responderam o questionário solicitado. $\mathrm{O}$ convite para responder este instrumento se deu para todos àqueles profissionais que ministraram disciplinas associadas ao projeto da monitoria, mesmo que por um curto período. Alguns desses professores já não faziam 
parte do quadro de professores da instituição na qual o projeto está alocado. No entanto, eles foram orientados a responder o questionário, mesmo estando sob essa condição, tendo em vista a valiosa contribuição para este trabalho.



Figura 9: Conceitos que os estudantes tiveram mais dificuldades em compreender.

Inicialmente, os professores foram questionados acerca do seu conhecimento da existência do projeto de monitoria. Dos professores que responderam, exatos $75 \%$ afirmaram conhecer o projeto. Em contrapartida, os outros $25 \%$ não o conhecia. Diante disso, percebe-se que embora uma grande parcela esteja familiarizada com o projeto, para uma outra parte dos professores o projeto ainda é desconhecido. Aqui se percebe uma necessidade constante de divulgação. Embora esse processo de divulgação seja feito efetivamente no início de cada semestre, entre os professores e estudantes das disciplinas, este resultado evidencia que a divulgação deve ser feita de forma contínua, e não de forma pontual. Do contrário, de um modo ou de outro, a existência da monitoria pode acabar sendo esquecida e, com isso, pode não alcançar seus objetivos e fins institucionais. É de grande importância que o professor conheça o projeto, pois ele pode exercer um papel importante em intermediar e incentivar os estudantes a procurarem a monitoria. Além disso, conhecendo o projeto, o professor poderia colaborar de forma mais efetiva com o estudante monitor, podendo contribuir com: compartilhamento de listas de exercícios, indicação das maiores dificuldades enfrentadas pelos discentes, agendamento de aula de exercícios com a presença do monitor, encontros extra aula com a presença do monitor e estudantes, dentre outros.

Na Figura 10 é exibido o resultado da interação do professor com a monitoria e vice-versa. $\mathrm{O}$ resultado sugere que os professores tiveram uma expressiva interação com o projeto. Por exemplo, os professores indicaram que divulgaram o projeto entre os estudantes e o estimularam a procurarem a monitoria (Frequentemente e muito frequente, $75 \%$ ); divulgaram os horários e o local para atendimento aos estudantes (Ocasionalmente, Frequentemente e muito frequente, 75\%); e foram informados sobre o local e o horário de atendimento aos estudantes (Frequentemente e muito frequente, $66,7 \%$ ). Por outro lado, esse mesmo resultado indica que houve pouca interação do professor com o estudante monitor. Por exemplo, um número expressivo de professores indicou que nunca ou raramente compartilhou material didático com o monitor (nunca e raramente, 
$58,3 \%)$, e nunca ou raramente procurou o monitor para discutir conteúdo visto em sala de aula (nunca e raramente, 66,7\%).

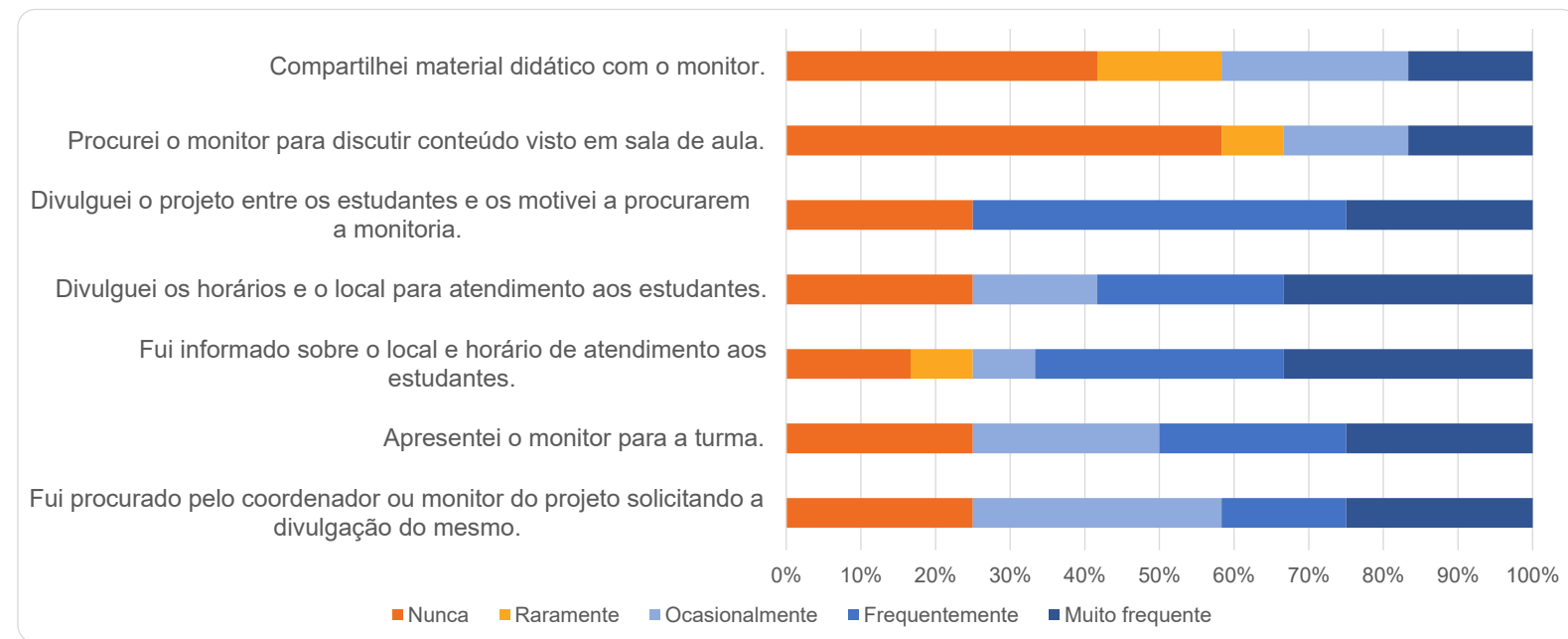

Figura 10: Interatividades do professor com a monitoria e vice-versa.

Deste modo, o resultado expresso na Figura 10 evidencia que, apesar de ter havido interação do professor com o projeto em si, houve uma baixa interação entre estes e os estudantes monitores. Isso mostra a necessidade e a urgência de promover ações que possibilitem uma maior interação entre esses dois importantes atores, de modo que essa interação gere bons resultados para o monitora de um modo geral.

A Figura 11(a) apresenta o nível de concordância dos professores para a afirmação: "Percebi melhorias após a contribuição do monitor no aprendizado do aluno". Nota-se que cerca de $42 \%$ (Concordo e Concordo totalmente) perceberam melhorias no aprendizado dos estudantes após contribuição do monitor. Isso corrobora com os princípios do trabalho do monitor, o qual prevê uma troca de conhecimentos entre estudante e monitor. Contudo, um percentual significativo (58\%) não soube indicar se houve melhoria no aprendizado dos estudantes. De fato, fazer uma avaliação do impacto ainda é um desafio, uma vez que nem sempre o professor está ciente de quais estudantes foram atendidos pelo monitor. A falta de interação entre professor e monitor pode ser um dos fatores que inviabilize essa avaliação. Neste sentido, promover estratégias que estreitem a relação entre esses dois atores pode potencializar uma melhor avaliação do impacto da monitoria. Contudo, é necessário criar instrumentos especializados que avaliem o impacto efetivo da monitoria no processo de aprendizagem dos estudantes.

A Figura 11(b) ilustra a percepção dos professores com relação ao processo de ensinoaprendizagem, proporcionada pelas atividades desenvolvidas pela monitoria. É possível perceber que a maioria dos respondentes atribuiu uma avaliação positiva para as atividades desenvolvidas (Bom, Muito bom e Excelente, 58\%). No entanto, uma parte indicou como razoável. Assim, mesmo sendo um valor bem inferior (8\%) às indicações positivas, é preciso elaborar estratégias para que se consiga contribuir mais efetivamente com o processo de ensino-aprendizagem dos discentes. Associado a esta questão, um dos professores indicou que a monitoria poderia ter atividades mais ativas, não esperar os alunos procurarem, mas marcar atividades específicas de 
resolução de problemas em dias e horários determinados. Deste modo, é importante investir em mais atividades que ponham o monitor em uma posição mais ativa durante esse processo. Vale destacar que, de um modo ou de outro, essa sugestão dada pelo professor se relaciona com as estratégias pedagógicas delineadas pelos estudantes monitores para melhoria da monitoria que foram definidas na Seção 5.1.4.

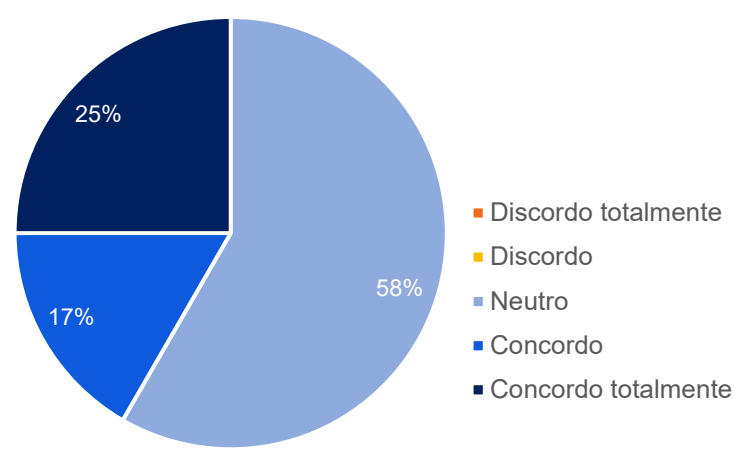

(a)

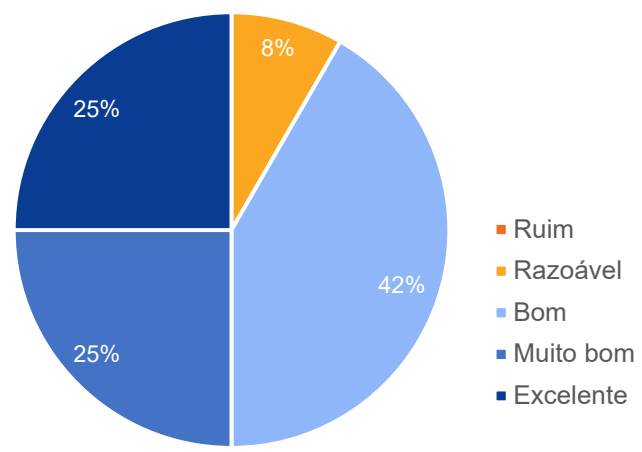

(b)

Figura 11: Em (a) concordância para a declaração: Percebi melhorias após a contribuição do monitor no aprendizado do aluno; Em (b) avaliação para a pergunta: Como avalia as atividades da Monitoria, no sentido de ensino/aprendizagem que é proporcionada à disciplina.

\section{Conclusão}

O presente estudo relata a experiência vivenciada na monitoria de Algoritmos e Programação da Universidade Estadual de Feira de Santana, sob a ótica dos estudantes, monitores e professores. Além disso, considerando a visão dos monitores, também elenca-se um conjunto de estratégias pedagógicas que poderiam ser empregadas para contribuir com o aperfeiçoamento das disciplinas apoiadas pelo programa de monitoria. Os resultados evidenciam que, apesar dos estudantes entenderem a monitoria como uma importante estratégia pedagógica, muitos não sentem a necessidade de procurar o monitor. Ao invés disso, muitas vezes preferem recorrer a outros meios alternativos, como à internet e aos colegas. Ainda com relação aos estudantes "monitorados", notou-se que eles estão abertos à inserção e à intensificação de ferramentas como Whatsapp, Telegram e Instagram, no sentido de tornar a monitoria mais dinâmica. Verificou-se também que as aulas remotas, em decorrência da pandemia, afetaram negativamente o entendimento dos conteúdos e conceitos de uma parte dos alunos. Ainda assim, os estudantes consideraram as disciplinas apoiadas pela monitoria como essenciais para alcançar seus objetivos profissionais, e também conseguiram enxergar a relação entre o conteúdo visto em aula e a prática.

Considerando os monitores, os resultados revelam que os monitores têm como maior motivação para o ingresso no programa a possibilidade de "Contribuir significativamente com o processo de aprendizagem de outros estudantes" e o "Interesse em ingressar na vida acadêmica/docente". Isso indica, entre outras coisas, o interesse dos estudantes por um aprendizado significativo, incluindo no seu processo formativo atividades dinâmicas. Os resultados também apontam, à luz dos relatos dos próprios monitores, que houve um aprimoramento na sua forma de ensinar, no 
seu conhecimento sobre linguagens de programação e na oralidade. Outros resultados revelam a importância do programa de monitoria no processo de ensino-aprendizagem, especialmente com relação à linguagem de programação e ao raciocínio lógico. No entanto, verificou-se que a ideia da monitoria ainda enfrenta resistência pelos discentes da instituição, evidenciado especialmente pelo fato da busca pela monitoria durante o período letivo não ocorrer com muita frequência. Isso exige, sobretudo por parte da Universidade, maior promoção dos programas de monitoria, em um processo constante de divulgação e de conscientização dos discentes da importância destas iniciativas no processo de aprendizagem. Como lições aprendidas, foram apontadas pelos monitores: o aprofundamento do conhecimento, o potencial da aprendizagem colaborativa, a importância do ensino personalizado, o impacto da motivação dos estudantes e, finalmente, a dificuldade com conceitos abstratos de computação.

Com relação aos professores, os resultados evidenciam que uma parte dos professores enxerga o projeto de monitoria como um recurso importante no processo de aprendizado do estudante, enquanto uma grande parcela não sabe ao certo o quanto a monitoria impacta no aprendizado dos estudantes. Verificou-se também que, embora os professores apoiem o projeto de monitoria, ainda falta uma maior interatividade entre eles e o monitor das disciplinas.

O estudo mostrou que o projeto de monitoria realizado na Universidade Estadual de Feira de Santana consegue atrair os alunos veteranos que estão interessados na área acadêmica para serem monitores, devido às possibilidades do treinamento de algumas habilidades essenciais à docência e aos profissionais da computação de modo geral. Em relação à interação entre o professor e os monitores, a produção de conteúdos didáticos ainda precisa ser melhorada. Por fim, nota-se que o programa de monitoria deve continuar buscando por estratégias que incentivem a participação dos estudantes "monitorados".

Como trabalhos futuros, pretende-se fazer um estudo aprofundado do impacto da monitoria no processo de ensino-aprendizagem, especialmente com relação à evasão e à reprovação. Além disso, deseja-se realizar uma análise sobre o desempenho acadêmico dos estudantes monitorados no componente curricular apoiado pela monitoria. De forma semelhante, espera-se avaliar também os estudantes monitores, observando o seu desempenho em suas outras disciplinas, do mesmo semestre da monitoria e de semestres subsequentes. Por fim, planeja-se colocar em prática as estratégias propostas neste estudo e, em seguida, avaliar o seu impacto.

\section{Artigo Premiado Estendido}

Esta publicação é uma versão estendida do artigo premiado no Simpósio Brasileiro de Educação em Computação (EduComp 2021), intitulado "A Experiência da Monitoria de Algoritmos e Programação em Cursos de Engenharia na Perspectiva dos Monitores”, DOI: 10.5753/educomp.2021.14484.

\section{Referências}

Abegg, I., Bastos, F. P., \& Müller, F. M. (2010). Ensino-aprendizagem colaborativo mediado pelo wiki do moodle. Educar em Revista, 205-218. doi: 10.1590/S0104-40602010000300014 [GS Search] 
Amato, D. T., \& Reis, A. C. (2016). A percepção dos monitores sobre o programa de monitoria do Ensino Superior do CEFET/RJ. Scientia Plena, 12(7). doi: 10.14808/sci.plena.2016.071302 [GS Search]

Assis, F., Borsatto, A. Z., Silva, P. D. D., Peres, P. L., Rocha, P. R., \& Lopes, G. T. (2006). Programa de monitoria acadêmica: percepções de monitores e orientadores. Rev. enferm. UERJ, 14(3), 391-397. [GS Search]

Ausubel, D. P. (1968). Educational psychology: a cognitive view. Holt, Rinehart and Winston: New York. [GS Search]

Ausubel, D. P. (2003). Aquisição e retenção de conhecimentos: uma perspectiva cognitiva. Lisboa: Plátano, 1. [GS Search]

Bazzo, W. A., \& Pereira, L. T. V. (2010). Introdução à engenharia: conceitos, ferramentas e comportamentos. Ed. da UFSC. [GS Search]

Belloni, M. L., \& Gomes, N. G. (2008). Infância, mídias e aprendizagem: autodidaxia e colaboração. Educação \& Sociedade, 29(104), 717-746. [GS Search]

Brasil (1968). Lei no 5.540, de 28 de novembro 1968. Diário Oficial da República Federativa do Brasil. Disponível em: http://www.planalto.gov.br/ccivil_03/leis/15540.htm. [Acesso em $12 / 06 / 2021]$

Brasil (1981). Decreto $\mathrm{n}^{\circ}$ 85.862, de 31 de março de 1981. Diário Oficial da União. Disponível em: http://www.planalto.gov.br/ccivil_03/Atos/decretos/1981/D85862.html. [Acesso em $12 / 06 / 2021]$

Brasil (1988). Constituição da república federativa do brasil de 1988. Brasília, DF: Senado Federal.. Disponível em: http://www.planalto.gov.br/ccivil_03/constituicao/constituicao.htm. [Acesso em 12/06/2021]

Brasil (1996). Lei no 9.394, de 20 de dezembro 1996. Diário Oficial da República Federativa do Brasil. Disponível em: http://www.planalto.gov.br/ccivil_03/leis/19394.htm. [Acesso em $12 / 06 / 2021]$

CNE (2002). Institui Diretrizes Curriculares Nacionais do Curso de Graduação em Engenharia. Resolução CNE/CES 11. Disponível em: http://portal.mec.gov.br/cne/arquivos/pdf/ CES112002.pdf. [Acesso em 12/06/2021]

Cordeiro, J. S., Almeida, N. N., Borges, M. N., Dutra, S. C., Valinote, O. L., \& Pravia, Z. M. C. (2009). Um futuro para a educação em engenharia no brasil: desafios e oportunidades. Revista de Ensino de Engenharia, 27(3), 69-82. [GS Search]

Cunha Júnior, F. R. (2017). Atividades de monitoria: uma possibilidade para o desenvolvimento da sala de aula. Educação e Pesquisa, 43(3), 681-694. doi: 10.1590/S1517-9702201707154754 [GS Search] 
Diesel, A., Martins, S. N., \& Rehfeldt, M. J. H. (2018). Aproximações entre as metodologias ativas de ensino e as tecnologias digitais de informação e comunicação: uma abordagem teórica. Conexões-Ciência e Tecnologia, 12(1), 38-44. doi: 10.21439/conexoes.v12i1.1074 [GS Search]

Dourado, L. F., \& Oliveira, J. F. (2009). A qualidade da educação: perspectivas e desafios. Cadernos Cedes, 29(78), 201-215. [GS Search]

Figuerêdo, J. S. L., Mascarenhas, R. S., \& Bittencourt, R. A. (2017). Disseminando a aprendizagem colaborativa atraves do ambiente canvas. CoRR, abs/1709.07537. Disponível em: https://arxiv.org/abs/1709.07537. [Acesso em 03/07/2021]

Freire, P. (2011). Pedagogia da autonomia: saberes necessários à pratica educativa (1st ed.). Paz e Terra. [Paulo Freire 1996 Pedagogia da autonomia: saberes necessários à prática educativa]

Frison, L. M. B. (2016). Monitoria: uma modalidade de ensino que potencializa a aprendizagem colaborativa e autorregulada. Pro-Posições, 27(1), 133-153. [GS Search]

Gadotti, M. (2010). Qualidade na educação: uma nova abordagem. Produção de terceiros sobre Paulo Freire; Série Livros. [GS Search]

Galvani, D., Silva, B. C., Menezes, B. M., Galvani, D. Z., \& Firpo, P. F. (2017). Monitorias em projeto pedagógico no ensino superior: Um relato de experiência. Anais do Salão Internacional de Ensino, Pesquisa e Extensão, 9(1). [GS Search]

Gatti, B. A. (2016). Formação de professores: condições e problemas atuais. Revista internacional de formação de professores, 1(2), 161-171. [GS Search]

Gil, A. C. (2002). Como elaborar projetos de pesquisa (Vol. 4). Atlas São Paulo. Disponível em: http://www.uece.br/nucleodelinguasitaperi/dmdocuments/gil_como_elaborar_projeto _de_pesquisa.pdf. [Acesso em 27/08/2021]

Godoy, E., \& Almeida, E. (2017). A evasão nos cursos de Engenharia e a sua relação com a Matemática: uma análise a partir do COBENGE. Educação Matemática Debate, 1(3), 339361. doi: 10.24116/emd25266136v1n32017a05 [GS Search]

Günther, H. (2006). Pesquisa qualitativa versus pesquisa quantitativa: esta é a questão? Psicologia: teoria e pesquisa, 22(2), 201-209. doi: 10.1590/S0102-37722006000200010 [GS Search]

Guzdial, M. J., \& Ericson, B. (2009). Introduction to computing and programming in python, a multimedia approach (2nd ed.). USA: Prentice Hall Press. [GS Search]

INEP (2010). Trajetória e estado da arte da formação em engenharia, arquitetura e agronomiavolume i: Engenharias. Disponível em: https://download.inep.gov.br/publicacoes/diversas/ temas_da_educacao_superior/trajetoria_e_estado_da_arte_da_formacao_em_engenharia _arquitetura_e_agronomia_vol_1_impresso.pdf. [Acesso em 12/06/2021]

INEP (2017). Censo da educação superior: notas estatísticas 2017. Disponível em: http://download.inep.gov.br/educacao_superior/censo_superior/documentos/2018/censo _da_educacao_superior_2017-notas_estatisticas2.pdf. [Acesso em 12/06/2021] 
Lins, L. F., Ferreira, L. M. C., Ferraz, L. V., \& Carvalho, S. S. G. (2009). A importância da monitoria na formação acadêmica do monitor. IX Jornada de ensino, pesquisa e extensão. [GS Search]

Lira, M. O., Nascimento, D. Q., Silva, G. C. L., \& Maman, A. S. (2015). Contribuições da monitoria acadêmica para o processo de formação inicial docente de licenciandos em ciências biológicas da UEPB. In $2^{\circ}$ Congresso Nacional de Educação (CONEDU. [GS Search]

Lourenço, M. R., \& Machado, J. (2017). Aprender juntos: projeto de apoio curricular entre pares. Revista Portuguesa de Investigação Educacional(17), 124-145. [GS Search]

Magalhães, L. D., Januário, I. S., \& Maia, A. K. F. (2014). A monitoria acadêmica da disciplina de cuidados críticos para a enfermagem: um relato de experiência. Revista da Universidade Vale do Rio Verde, 12(2), 556-565. doi: 10.5892/ruvrd.v12i2.1610 [GS Search]

Martinelli, C. S., \& Bartholomeu, D. (2007). Escala de motivação acadêmica: uma medida de motivação extrínseca e intrínseca. Avaliaçao Psicologica: Interamerican Journal of Psychological Assessment, 6(1), 21-31. [GS Search]

Matoso, L. M. L. (2014). A importância da monitoria na formação acadêmica do monitor: um relato de experiência. CATUSSABA-ISSN 2237-3608, 3(2), 77-83. Disponível em: https:// repositorio.unp.br/index.php/catussaba/article/view/567. [Acesso em 12/06/2021]

Mazur, E. (1999). Peer instruction: A user's manual. American Journal of Physics, 67(4), 359360. doi: 10.1119/1.19265 [GS Search]

Nascimento, F. B., \& Barletta, J. B. (2011). O olhar do docente sobre a monitoria como instrumento de preparação para a função de professor. Rev Cereus, 3(1), 57-75. Disponível em: http://ojs.unirg.edu.br/index.php/1/article/view/57. [Acesso em 12/06/2021]

Pelizzari, A., Kriegl, M. L., Baron, M. P., Finck, N. T. L., \& Dorocinski, S. I. (2002). Teoria da aprendizagem significativa segundo Ausubel. Revista PEC, 2(1), 37-42. [GS Search]

Pereira, F. I. (2017). Aprendizagem por pares e os desafios da educação para o senso crítico. International Journal on Active Learning, 2(1), 6-12. doi: 10.15202/25262254.2017v2n1p6 [GS Search]

Piva Júnior, D., \& Freitas, R. L. (2010). Estratégias para melhorar os processos de abstração na disciplina de algoritmos. In Brazilian Symposium on Computers in Education (Simpósio Brasileiro de Informática na Educação-SBIE). [GS Search]

Reis, V. W., Cunha, P. J., \& Spritzer, I. (2012). Evasão no ensino superior de engenharia no brasil: um estudo de caso no cefet/rj. In XL Congresso Brasileiro de Educação em Engenharia. Belém do Pará. [GS Search]

Ribeiro, L., Foss, L., \& Cavalheiro, S. A. C. (2017). Entendendo o pensamento computacional. CoRR, abs/1707.00338. Retrieved from http://arxiv.org/abs/1707.00338 [GS Search]

Robins, A., Rountree, J., \& Rountree, N. (2003). Learning and teaching programming: A review and discussion. Computer Science Education, 13(2), 137-172. doi: 10.1076/csed.13.2.137.14200 [GS Search] 
Santana, B. L., Figuerêdo, J. S. L., \& Bittencourt, R. A. (2017). Motivação de estudantes nonmajors em uma disciplina de programação. In Anais do XXV Workshop sobre Educação em Computação. Porto Alegre, RS, Brasil: SBC. doi: 10.5753/wei.2017.3545 [GS Search]

Severino, A. J. (2009). Expansão do ensino superior: contextos, desafios, possibilidades. Avaliação: Revista da Avaliação da Educação Superior (Campinas), 14(2), 253-266. [GS Search]

Silva, A. S. P., Bueno, M. R. P., Amaral, M. A. F., Sellmann, M. Z., \& Koehler, S. M. F. (2012). Inovação didática-projeto de reflexão e aplicação de metodologias ativas de aprendizagem no ensino superior: uma experiência com “peer instruction”. Janus, 9(15). [GS Search]

Silva, E. L., \& Menezes, E. M. (2001). Metodologia da pesquisa e elaboração de dissertação. [GS Search]

Silva, J. B. (2020). A teoria da aprendizagem significativa de David Ausubel: uma análise das condições necessárias. Research, Society and Development, 9(4), e09932803-e09932803. doi: 10.33448/rsd-v9i4.2803 [GS Search]

Silveira, E., \& Sales, F. (2016). A importância do programa de monitoria no ensino de biblioteconomia da Universidade do Estado de Santa Catarina (UDESC). In CID: Revista de Ciência da Informação e Documentação, 7(1), 131-149. doi: 10.11606/issn.2178-2075.v7i1p131-149 [GS Search]

Tarouco, L. M. R., Roland, L. C., Fabre, M. C. J. M., \& Konrath, M. L. P. (2004). Jogos educacionais. RENOTE: revista novas tecnologias na educação, 2(1). doi: 10.22456/16791916.13719 [GS Search]

Tavares, R. (2004). Aprendizagem significativa. Revista conceitos, 10(55). [GS Search]

UEFS (2010). Resolução consepe resolução consepe 208/2010. Conselho Superior de Ensino, Pesquisa e Extensão - CONSEPE. Disponível em: http://www.sei.uefs.br/arquivos/ File/Docs_SEI/BasedeConhecimento/BolsaAcademica_Pagamento/MONITORIA_resolucao _consepe_208_2010.pdf. [Acesso em 12/06/2021]

UEFS (2021). Monitoria. Disponível em: http://www.prograd.uefs.br/modules/conteudo/ conteudo.php?conteudo=23. [Acesso em 12/06/2021]

Vasconcelos, C., Praia, J. F., \& Almeida, L. S. (2003). Teorias de aprendizagem e o ensino/aprendizagem das ciências: da instrução à aprendizagem. Psicologia escolar e educacional, 7(1), 11-19. doi: 10.1590/S1413-85572003000100002 [GS Search]

Watson, C., \& Li, F. W. (2014). Failure rates in introductory programming revisited. In Proceedings of the 2014 conference on innovation \& technology in computer science education (p. 39-44). New York, NY, USA: Association for Computing Machinery. doi: 10.1145/2591708.2591749 [GS Search]

Zanetti, H., \& Oliveira, C. (2015). Práticas de ensino de programação de computadores com robótica pedagógica e aplicação de pensamento computacional. In Anais dos workshops do congresso brasileiro de informática na educação (Vol. 4, p. 1236). doi: 10.5753/cbie.wcbie.2015.1236 [GS Search] 